\title{
El Libro de los Cofrades del Santísimo Rosario de la Cartuja de Granada: estudio y transcripción de la memoria de una hermandad monástica
}

\author{
José Antonio DíAz Gómez
}

Fecha de recepción: Septiembre 2020.

Fecha de aceptación: Septiembre 2020.

\section{Sumario:}

En este trabajo se ofrece el estudio y transcripción literal del único documento conservado de la Cofradía del Rosario de la Cartuja de Granada (1578-1796). Se trata de una corporación eminentemente monástica y con escasa participación seglar, que contó con una vida irregular, a causa de los frecuentes rechazos de la orden frente a un uso devocional que podía transformar las propias costumbres piadosas de los cartujos. Con todo, las generosas indulgencias que se desprendían de la conformación y pertenencia de esta peculiar hermandad, posibilitaron la existencia de periodos de aceptación, todo lo cual se refleja en este libro que hace posible conocer un poco mejor la vida de la comunidad cartuja de Granada.

\section{Palabras clave:}

Santo Rosario; Cofradías; Orden de la Cartuja; Documentación histórica; Granada (España); Edad Moderna.

\section{The memory of a monastic brotherhood in Granada Charterhouse through the study and transcription of Libro de los Cofrades del Santísimo Rosario ${ }^{2}$}

\begin{abstract}
:
This paper presents the study and literal transcription of the only preserved document of the Brotherhood of the Holy Rosary of the Charterhouse of Granada (1578-1796). It was an eminently monastic corporation with little secular participation, which had an irregular life. The reason was the frequent rejections of the Carthusian Order in the face of a devotional use that could transform the pious customs of the Carthusians. However, the generous indulgences that emerged from the formation and membership of this peculiar brotherhood, made possible the existence of periods of acceptance reflected in this book that makes possible to know a little better the life of the Carthusian community of Granada.
\end{abstract}

\section{Keywords:}

Holy Rosary; Catholic brotherhoods; Carthusian Order; Historical files; Granada (Spain); Early Modern Period.

\footnotetext{
${ }^{1}$ Doctor internacional en Historia y Artes, Grupo HUM-362 "Arte y cultura en la Andalucía moderna y contemporánea" (Universidad de Granada), profesor del Departamento de Historia del Arte de la Universidad de Sevilla, https://orcid.org/0000-0002-1910-2731<jdiazg@us.es>.

${ }^{2}$ Book of the Brothers of the Holy Rosary.
} 


\section{La Orden de la Cartuja y el rosario}

Una de las tradiciones más sólidas que, con orgullo satisfecho, blanden los cartujos aún a día de hoy, es la de haber sido su vetusta orden la cuna que vio alumbrar el ejercicio piadoso del rosario, eso sí, en su formato más primario y tan diferente de la estructura enraizada por los dominicos en la piedad popular a lo largo de la Edad Moderna. Así, el principal estudioso del fenómeno rosariano dentro del panorama español actual, el historiador y teólogo Carlos Romero Mensaque, apoya asimismo en sus estudios el origen monástico de este rezo, vinculado a las iniciativas particulares que, más allá de las plegarias canónicas, el monje desarrollaba en la soledad y silencio de su celda, amparado por la espiritualidad del benedictinismo y el cartujanismo ${ }^{3}$.

Ciertamente, las investigaciones desarrolladas a este respecto, apuntan a que el origen estricto del rezo del rosario se debe localizar entre los muros de la desaparecida Cartuja de Meyriat, que había sido fundada hacia el año 1116 en las proximidades de la población lorenesa de La Bresse ${ }^{4}$. De hecho, podría decirse incluso que la oración del Avemaría adquiere su perfeccionamiento en la fórmula que ha llegado a nuestros días, gracias al devenir del rosario cartujano. Así pues, la jaculatoria «Santa María, Madre de Dios, ruega por nosotros pecadores, ahora y en la hora de nuestra muerte», que pasa por ser considerada como segunda parte de la plegaria mariana por excelencia, goza de una antigüedad que se remonta al año 1521 en que, por vez primera, aparece canónicamente asentada dentro del Oficio Parvo del Breviario cartujano, completando la tradicional salutación del ángel Gabriel ${ }^{5}$, en base a la plegaria formulada en 1495 por el dominico Girolamo Savonarola en su Esposizione sobre el Avemaría ${ }^{6}$.

Como se anunciaba, a esta fórmula definitiva se llega gracias a las particularidades del modo de rezar el rosario desde sus orígenes en la Cartuja, los cuales se retrotraen a la segunda mitad del siglo XIII cuando, por influjo de las costumbres benedictinas, se extiende en los cenobios de aquella la pra-

${ }^{3}$ Carlos J. Romero Mensaque, "Los comienzos del fenómeno rosariano en la España moderna. La etapa fundacional: siglos XV y XVI”, Hispania Sacra LXVI, Extra II (2014): 245-246.

${ }^{4}$ Javier Ibáñez y Fernando Mendoza, "El culto a la Santísima Virgen en la Cartuja. El Santo Rosario", Scripta de María 1 (1978): 205-213.

5 Ídem: 181-184.

${ }^{6}$ Luis Antequera Becerra, El cristianismo desvelado. Respuestas a las 103 preguntas más frecuentes sobre el cristianismo (Madrid: EDAF, 2007), 533-541. Et: Girolamo Savonarola, "Esposizione sopra l'orazione della Vergine", Marian Library Studies 10 (1978): 81-105 [Transcripción del original de 1495]. Et: Marcelin Chéry, La Théologie du Saint Rosaire (París: Poussielgue, 1869), vol. II, 47-49. 
xis mortificadora de elevar a la Virgen, en la soledad de la celda, un salterio paralelo al propio de las Horas canónicas, consistente en el ofrecimiento de entre 25 y 150 padrenuestros y otros tantos avemarías, recitados en serie y separadamente ${ }^{7}$. Será ya a comienzos del siglo XIV cuando, formalmente, este ejercicio piadoso comience a ser denominado como Salterio de María, recitado de forma independiente con respecto al Oficio Parvo de Beata, que el monje reza en la soledad de su celda de forma previa a la correspondiente Hora canónica ${ }^{8}$. Además, su motivación vendría a quedar justificada por el cariz compensatorio que adoptaba con respecto a aquellos legos y donados cuya escasa formación les impedía seguir la Liturgia de las Horas con normalidad $\mathrm{y}$, de esta manera, podían contar con un salterio que recitar de forma paralela mientras los monjes letrados hacían lo propio en el coro 9 .

Así, avanzando en la decimocuarta centuria, el rezo del rosario adquirirá una nueva morfología en la cartuja alemana de Tréveris, de manos del monje Domingo de Tréveris, quien estructura esta devoción en la recitación cadenciosa de 150 salutaciones del ángel Gabriel -es decir, del Avemaría propiamente dicho-. Éstas, a falta aún de la jaculatoria definitiva antes mencionada, se repartían en tres tandas de 50, distribuidas en cada tres días y que se completaban con las correspondientes 50 cláusulas, diferentes todas ellas, pues cada una consistía en una breve acción de gracias a santa María por el papel desempeñado en un pasaje evangélico concreto, sobre el cual se meditaba ${ }^{10}$. A fin de ilustrar este sistema con un ejemplo, se facilita a continuación la primera cláusula del rosario cartujano: «Dios te salve María, llena eres de gracia, el Señor es contigo, bendita tú eres entre todas las mujeres y bendito es el fruto de tu vientre Jesús, [a continuación se incorpora la cláusula] concebido por el Espíritu Santo en el anuncio del Ángel [y se medita sobre este misterio]» ${ }^{11}$. Estas cláusulas se dividían en cinco decenas, cada una de ellas precedidas del rezo de un Padrenuestro y rematadas con la recitación del Gloria.

Tal y como Romero Mensaque ha sabido diferenciar a la perfección ${ }^{12}$, esta configuración del rezo del rosario se extendería desde el siglo XIII al XVI en una primera fase evolutiva, que comprendería su origen y consolidación en la

${ }^{7}$ Ibáñez y Mendoza, “El culto a la Santísima Virgen...”: 205-213.

${ }^{8}$ Rosendo Roing, Diálogos en la Cartuja (Burgos: Cartuja de Miraflores, 2012), 66.

9 Ídem: 115. Et: Ibáñez y Mendoza, “El culto a la Santísima Virgen...”: 162-166.

${ }^{10}$ Ibáñez y Mendoza, “El culto a la Santísima Virgen...”: 2012-2013.

${ }^{11}$ Marcelin Chéry, Histoire générale du Rosaire et de sa confrérie (París: Poussielge, 1869), 47-62.

${ }^{12}$ Carlos J. Romero Mensaque, "E1 Rosario y sus cofradías en Andalucía. Una aproximación histórica”, Hispania Sacra LXII, 126 (2010): 622-626. 
Orden de la Cartuja, para dar el salto a otras órdenes monásticas y, desde ahí, afianzarse como una devoción privada propia del carisma contemplativo y observante ${ }^{13}$. Esta expansión intra claustra es la que explica su implantación en la Orden de Predicadores que, durante la Contrarreforma, hará del rosario una insignia propiamente dominica en la extensión de su misionado popular, de acuerdo con los parámetros de la denominada como devotio moderna en la Baja Edad Media ${ }^{14}$.

Hasta tal punto se producirá una simbiosis entre lo dominicano y lo rosariano que, para 1470, el dominico observante Alano de la Roca estaba ya fundando en la entonces aún holandesa ciudad de Douai la primera confraternidad de seglares dedicada al ejercicio del Salterio de María o, lo que es lo mismo, la primera cofradía rosariana de la historia ${ }^{15}$. Con ello, aparecería ya también el formato definitivo del rezo, articulado en torno a 15 misterios que se agrupan en tandas de cinco en las que, respectivamente, se medita sobre los principales misterios evangélicos en que se reflejan los gozos, los dolores y las glorias de la Virgen María ${ }^{16}$. Cada misterio iría precedido del rezo de un Padrenuestro y culminado por un Gloria, siendo su desarrollo más sistemático para su práctica a cargo de unos seglares menos hechos a los largos tiempos de meditación ${ }^{17}$.

A partir del año 1571, se abrirá una segunda etapa que alcanzará hasta 1690 aproximadamente, en la que el rosario sale de los claustros cenobíticos, para convertirse en un culto de carácter institucional y elitista. Y es que 1571 es el año de la batalla de Lepanto, en que la victoria de la Liga Santa sobre el Imperio otomano el 7 de octubre, es atribuida por el papa dominico Pío V a la intercesión de la Virgen por las súplicas que estaba ofreciendo aquella jornada la Cofradía del Rosario de la Basílica de Santa María sopra Minerva ${ }^{18}$. Aquella actuación no fue sino una concienzuda estrategia que le valió al pontífice

${ }^{13}$ Cfr. André Duval, "Rosaire”, en M. Viller, F. Cavallera y J. Gibert (coords.), Dictionnaire $d u$ Spiritualité, Ascetique et Mistique (París: Beauchesne, 1988), vol. XIII, 937-980. Et: Luis G. Alonso Getino, Origen del Rosario y leyendas castellanas del siglo XIII sobre Santo Domingo de Guzmán (Vergara: Tipografía del Santísimo Rosario, 1925).

${ }^{14}$ Romero Mensaque, “Los comienzos del fenómeno...": 246-247.

${ }^{15}$ Riccardo Barile, Il Rosario, Salterio della Vergine (Bolonia: Edizioni Dehoniane, 1990), $45-72$

${ }^{16}$ Conviene no olvidar que, desde el año 2002 y por iniciativa del papa Juan Pablo II, el rosario cuenta con cinco nuevos misterios llamados Luminosos, que amplían las meditaciones a la vida pública de Cristo. Cfr. Santa Sede, Carta apostólica "Rosarium Virginis Mariae”, octubre 16, 2002.

${ }^{17}$ Romero Mensaque, “Los comienzos del fenómeno...”: 249-251.

${ }^{18}$ Romero Mensaque, "El Rosario y sus cofradías...”: 623. 
para que la devoción a la Virgen del Rosario irrumpiese al fin en todo el orbe católico como un rayo imparable que prontamente, en 1573, traería la consolidación de su festividad en el primer domingo de octubre por el papa Gregorio XIII, mediante breve que asimismo promovía la dedicación de altares y capillas a esta advocación, al tiempo que se reservaba el primer domingo de cada mes como día especialmente dedicado a la devoción del rosario. De este modo, es como el viejo rezo monástico se convierte en una suerte de pequeña liturgia mariana institucionalizada por la Iglesia a través de las cofradías de corte elitista, dedicadas a este fin y cuyo control quedaba exclusivamente en manos de los dominicos ${ }^{19}$.

Empero, poco más de un siglo después, hacia 1690 como se señalaba, estas dinámicas cambiarían, abriéndose así la etapa definitiva en la evolución de la piedad rosariana, la cual se extiende hasta la contemporaneidad pues, paulatinamente, el rezo del rosario se irá convirtiendo en un fenómeno popular, casi de masas, que escaparía a la jurisdicción institucional. Romero Mensaque señala como punto de partida el inicio de la celebración de rosarios públicos, callejeros y abiertos a la religiosidad del pueblo, del que marca como primigenio el organizado en 1690 en Sevilla por el dominico Pedro de Santa María y Ulloa $^{20}$. Esta peculiar celebración, encuadrada dentro del tipo de espiritualidad popular promovida en los dominios hispánicos tras el Concilio de Trento (1545-1563), sentaría un precedente que se extendería de manera fulgurante por todos estos territorios, siendo ya el rosario una praxis de dominio enteramente popular, con independencia de todo estatus social.

El punto paradójico de todo este desarrollo histórico, radica en que la Orden de la Cartuja, pese al ortodoxo celo con que siempre ha tratado de preservar sus ritos, sin embargo, irá viendo renovada su fórmula rosariana de acuerdo con los patrones dominicos. Ello ocurrirá especialmente a partir del siglo XVI, momento en que en el interior de las cartujas se está rezando ya el rosario de 15 misterios e incluso se va vislumbrado la peculiar conformación de cofradías monásticas de cariz rosariano, cuya razón de ser se expondrá en el siguiente apartado. Esta situación se produjo porque el rezo del rosario se acabó convirtiendo en un "arma devocional" de tanto alcance y fuerza que su renovación corría pareja al propio relevo generacional entre los nuevos monjes que profesaban. Por tanto, podría decirse que el rosario experimentó una deriva por la cual sale de la Cartuja para volver a ella dos siglos más tarde

\footnotetext{
${ }^{19}$ Chéry, Histoire générale..., 73-87.

${ }^{20}$ Romero Mensaque, “El Rosario y sus cofradías...”: 623-624. Et: Miguel L. López-Guadalupe Muñoz, "Expansión de las cofradías del Rosario en la diócesis de Granada en la época moderna", en H. Paz Castaño y C. J. Romero Mensaque (coords.), Congreso Internacional del Rosario. Actas, 379-389. Sevilla: RD Editores, 2004.
} 
completamente transfigurado, hasta el punto de haber roto con sus propios orígenes cartujos en el plano identitario.

\section{Idiosincrasia de una cofradía rosariana en la Cartuja}

El monje cartujo, como todo cristiano que se sujete a los predicamentos del Evangelio, debe vivir sin ser del mundo, pero está en el mundo y, por ende, permanece también sujeto a sus anhelos y sus miedos. Así lo reflejó Vicente Carducho en la pintura con que cerró el ciclo de lienzos dedicados a la historia y carisma cartujanos para el claustro mayor de la Cartuja de El Paular (1626-1632 $)^{21}$. Este cuadro, tradicionalmente bautizado por la historiografía como Aparición de la Virgen a un hermano cartujo, realmente es una alegoría planteada en los diseños que el cartujo Juan de Baeza proporcionó al pintor como modelo para los lienzos ${ }^{22}$. En ella se plasma el modo en que la oración reconforta al monje frente a los terrores y tentaciones que con harta frecuencia le acechan en la soledad de su celda, aquí representados a la manera de monstruos antediluvianos.

Traigo a colación el breve comentario de esta alegoría, dado que los humanos temores compartidos por los cartujos se encuentran en la raíz del sentido justificativo de la existencia de una cofradía monástica, conformada por los mismos habitantes del cenobio que conviven compartiendo idénticos piadosos fines. Si la vida del monje, per se, constituye una vía de vivencia de la espiritualidad y búsqueda de la salvación, con sus normas y costumbres, ¿qué sentido tiene albergar una nueva congregación interna con los mismos integrantes y objetivos? La respuesta a este interrogante estriba sencillamente en las generosísimas indulgencias que se desprendían de las bulas promulgadas al hilo de la devoción del rosario por los papas Inocencio VIII (1482-1492), Pío V (1566-1572), Gregorio XIII (1572-1585), Clemente IX (1667-1669), Clemente X (1670-1676) e Inocencio XI (1676-1689) ${ }^{23}$.

Así, para garantizar el control dominico, desde las disposiciones del papa Pío V, las indulgencias relativas al rezo del rosario se ganaban únicamente mediante el formato difundido por los hijos de santo Domingo de Guzmán, descartando así cualquier posibilidad de éxito de las demás fórmulas rosa-

${ }^{21}$ E. Barceló de Torres y L. Ruiz Gómez, La recuperación de El Paular (Madrid: Ministerio de Educación, Cultura y Deporte - Subdirección General del IPCE, 2013), 185-190.

${ }^{22}$ Félix Delgado López, "Juan de Baeza y las pinturas de Vicente Carducho en la cartuja del Paular”, Locus amoenus 4 (1998-1999): 185-200.

${ }^{23}$ Cfr. Chéry, La Théologie..., vol. II. 
rianas, por muy venerable que resultase su antigüedad. Por supuesto, como cualquier otra concesión de indulgencia, las condiciones fundamentales para ganarla se basaban en poseer la intención de obtenerla, hallarse en estado de gracia y haber adquirido la bula de la Santa Cruzada ${ }^{24}$. A todo ello, en este caso específico, se añade la obligatoriedad de ser cofrade del rosario, para lo cual bastaba únicamente con constar inscrito en el libro de cofrades de cualquier corporación rosariana sujeta a los requisitos de aprobación pontificia, circunstancia que se encargaba de verificar el correspondiente provincial de la Orden de Predicadores ${ }^{25}$.

Consecuentemente, las nuevas generaciones de cartujos de la Edad Moderna ingresaban en sus monasterios corriéndole por las venas el pleno fervor rosariano. De este modo, al ser las costumbres cartujanas contrarias a toda vinculación con el plano seglar, a fin de facilitar la obtención de las indulgencias del rosario, se promovieron dentro de ciertas cartujas corporaciones propias, de modo que los monjes pudiesen quedar inscritos en el respectivo libro de cofrades, sin infringir las normas de la orden. Probablemente, a esta iniciativa también contribuyó el hecho de que, una vez inscrito, el cofrade no adquiría ningún tipo de obligación, más allá de las que voluntariamente quisiera o pudiera aportar. Por tanto, no hay ningún tipo de compromiso económico ni de asistencia regular a cultos o actividades caritativas específicas. Bastaba con que el nombre del individuo interesado se reflejase en el libro de cofrades para que éste se beneficiase de las garantías espirituales e indulgencias que se derivaban del rezo del rosario, así como de «todas las misas, oraciones, ayunos, disciplinas, trabajos y buenas obras que mediante la Gracia divina por toda la Cristiandad hicieren, así los cofrades del Rosario, como los frailes y monjas de la Sagrada Orden de Predicadores ${ }^{26}$.

Con esta forma de proceder, en torno a los dominicos se gestaba una suerte de gran extensión terciaria, conformada por multitud de seglares y eclesiásticos de diverso carisma con el único vínculo de la devoción al rosario. Además, un acicate crucial para propiciar el asociacionismo alrededor del rosario fue el hecho de que se podía inscribir en los libros de cofrades tanto a vivos como a difuntos, los cuales se beneficiaban de las indulgencias de forma indistinta. Incluso, se permitía que un cofrade pudiese apuntar a sus allegados, vivos o

${ }^{24}$ Orden de Predicadores, Sumario de las indulgencias concedidas a los cofrades del Santísimo Rosario y Dulce Nombre de Jesús, con otras comunes a todos los fieles (Madrid: Imprenta y Fundición de D.E. Aguado, 1845), 3.

25 Ídem.

${ }^{26}$ Archivo Histórico Nacional [AHN], sección Clero Secular-Regular, libro 3606 "Libro de los cofrades del Santísimo Rosario de Nuestra Señora, que se va escribiendo", fol. 6r. 
no, sin conocimiento de estos y hasta se garantizaba, para la obtención de las diversas garantías espirituales, no ser «necesario que las dichas personas estén en gracia de Dios, pero será infinitamente mejor [si lo están] $\gg^{27}$.

Por lo demás, naturalmente, las indulgencias se ganaban en los primeros domingos de cada mes, en las fiestas de la Virgen, en las grandes solemnidades o durante la Cuaresma; así también, por rezar el rosario o parte del mismo en cualquier momento, o realizar algún acto de piedad en un altar o espacio de culto dedicado a la advocación mariana del Rosario. Con ello, conviene apuntar que se trataba de indulgencias especialmente dadivosas, sobre todo en lo que a acortar tiempos de purgatorio se refiere. Por poner un ejemplo extraído del sumario de indulgencias publicado por los dominicos para estas cofradías, por rezar una parte del rosario se ganaban 120.010 años, 120.010 cuarentenas y 180 días de indulgencia; y si esto se hacía usando un rosario previamente bendecido, a tamaño beneficio espiritual se sumaban 100 días más por cada Padrenuestro y cada Avemaría. Otra garantía extra la constituía, como se anunciaba, cada visita devota al altar en que estuviese asentada la cofradía, que comportaba otro centenar de jornadas de indulgencia ${ }^{28}$.

De este modo, lo que se va a encontrar en algunas cartujas es un libro de cofrades afanados por beneficiarse de tan generosas concesiones espirituales -a cuyo frente se situaba el padre prior o, por delegación de este, el padre vicario-, junto con la existencia del altar específico al que se vinculaba la cofradía y que, tarde o temprano, acabaría siendo presidido por una representación de la Virgen del Rosario. Con todo, no conviene pensar que ésta fue una praxis común en todo el panorama cartujano. En territorio de las coronas de Castilla y Aragón, de las 23 cartujas que se llegaron a levantar entre los siglos XIII y $\mathrm{XVII}^{29}$, tan sólo cuatro de ellas contaron con una cofradía del rosario sujeta al reconocimiento pontificio y de las que, en consecuencia, ha quedado constancia documental.

Y es que, como después se analizará en el caso granadino, el interés de los monasterios cartujos por poseer este tipo de congregación fue desigual y muy irregular. Posiblemente empujada por la fiebre rosariana que se vivía en la urbe, la Cartuja de las Cuevas de Sevilla fue la primera en contar con una cofradía afín en 1570. Así, emulando el modelo hispalense, sucumbieron pocas décadas después las comunidades de la Asunción (Granada) en 1578,

\footnotetext{
${ }^{27}$ Orden de Predicadores, Sumario de las indulgencias ..., 4.

${ }^{28}$ Orden de Predicadores, Sumario de las indulgencias ..., 7-22.

${ }^{29}$ Juan Mayo Escudero, Expansión y organización de la Orden de la Cartuja (Salzburg: Universität, Institut fur Anglistik und Amerikanistik, 2002), 26-28.
} 
de Miraflores (Burgos) en 1624 y de Porta Coeli (Valencia) en 1628 $8^{30}$. Por tanto, teniendo en cuenta la simpleza de los trámites y exigencias para poner en marcha una cofradía de este tipo en la clausura cartujana, si en el resto de cartujas españolas hubo algún conato fundacional, éste no debió de prosperar, bien desde un desinterés mayoritario, bien desde una oposición del Capítulo a permitir el más mínimo subterfugio a la observancia tradicional de la orden.

En todo ello también debió tener un peso sustancial la mayor o menor simpatía que el prior de turno albergase para con esta causa. El hecho de que el libro de cofrades de Granada, que a continuación será analizado, presente grandes vacíos cronológicos entre prioratos, evidencia que la iniciativa se paralizó y se reactivó en distintos momentos de la historia del monasterio. Además, otra nota común que parecen haber compartido estos cenobios que contaron con cofradías formalmente reconocidas, es que tuvieron en algún momento entre sus filas a un entusiasta impulsor de la devoción rosariana. Tal fue el caso de Sevilla, donde profesó Gaspar Gorricio de Novara (el mismo que fue amigo, confesor y consejero de Cristóbal Colón) ${ }^{31}$, quien en 1491 publicó un tratado con una serie de instrucciones y «contemplaciones» para la ejecución del rezo, titulado Rosarium Beatae Virginis Mariae, et alia opuscula y destinado a los cofrades del rosario de Sevilla, con los que manifiesta una estrecha cercanía en el proemio ${ }^{32}$.

Por su parte, entre los años 1624 y 1629, Granada tendría como prior al padre Pedro Manuel Deza quien ${ }^{33}$, si bien no deja constancia alguna en el libro de cofrades, no duda en consolidar los espacios del monasterio dedicados a esta devoción, al encargar al lego y genial pintor Juan Sánchez Cotán, el gran lienzo de La Virgen del Rosario ${ }^{34}$ en el que cinco cartujos de Granada (Cotán entre ellos) son retratados orantes ante una pretendida aparición de la Virgen en la silla prioral del Capítulo, la cual hace entrega del rosario al prior (fig. 1). Precisamente, al padre Deza, cuando aún era monje profeso de El Paular, se le

${ }^{30}$ Romero Mensaque, "Los comienzos del fenómeno...”: 257. Et: Cfr. Anónimo cartujo, El Santo Rosario en la Cartuja (Salzburg: Universität, Institut fur Anglistik und Amerikanistik, 1983).

${ }^{31}$ Romero Mensaque, “Los comienzos del fenómeno...”: 257. Et: Antonio Linage Conde, “Tentativas cartujanas en la América Española”, Hispania Sacra 80 (1987): 405-431.

${ }^{32}$ Cfr. S. Cantera Montenegro y A. Torrego Casado (eds.), Contemplaciones sobre el rosario de Nuestra Señora (Salzburg: Universität, Institut fur Anglistik und Amerikanistik, 2002). He aquí una interesante traducción al castellano de la obra rosariana de Gorricio de Novara, realizada a partir del original conservado en los fondos del British Museum.

${ }^{33}$ José A. Díaz Gómez, "La Cartuja de la Asunción (Granada): datos inéditos para la revisión de su historia”, Archivo Teológico Granadino 82 (2019): 46-47.

${ }^{34}$ Emilio Orozco Díaz, El pintor fray Juan Sánchez Cotán. Granada: Universidad - Diputación Provincial, 1993, 108. 
debe el encargo al genial Félix Lope de Vega y Carpio de los versos intitulados Himno de oro o Rosario rítmico ${ }^{35}$, con cuya musicalidad se quiso facilitar un instrumento que simplificase el aprendizaje de las cláusulas cartujanas del rosario y sus meditaciones. Este texto es, además, una férrea defensa del origen y formato del rosario cartujano.

Aunque las crónicas cuentan que la composición resultante de Lope de Vega no terminó de contentar al padre Deza y el literato tuvo que buscar defensores de su trabajo, tal vez estas cuidadosas preocupaciones nos permitan vislumbrar el porqué del escaso predicamento de la cofradía rosariana en la Orden de la Cartuja, así como los vacíos documentales en las pocas casas en que consiguió establecerse. El hecho de que el prior Deza, firme difusor del rosario, no aparezca en el libro de cofrades de Granada y sí en la promoción de otras iniciativas rosarianas propias, habla de un gran celo; un celo que se da por la defensa de la tradición rosariana que es propia de la Cartuja, frente a las fórmulas de los dominicos que amenazaban con suplantar incluso dentro de sus monasterios a aquellas derivadas de las propias costumbres cartujanas. Por ello, a pesar de que este estudio se centra únicamente en contextualizar y desgranar el libro de cofrades de la cartuja granadina, será interesante una futura ampliación que analice el clima que a este respecto se respiraba en las demás cartujas europeas e incluso a la luz de la documentación de los Capítulos generales.

Por último, tal vez cupiera valorar la posibilidad de una cierta resistencia de la Cartuja frente al asociacionismo rosariano por temor a la más mínima injerencia en su amplia autonomía por parte de los dominicos. Sin embargo, creo que esta opción puede ser descartada desde el primer momento a la luz del mismo documento histórico que nos ocupa, puesto que la intervención de la Orden de Predicadores en estas cofradías cartujanas se limitó en todo momento a aprobar su constitución y reconocer el hermanamiento espiritual que comportaba la existencia del libro de cofrades. Ello ocurría en la andadura inicial de la congregación, sin que los dominicos se volviesen a ocupar de la misma a posteriori. De hecho, en el caso granadino no existió, a este respecto, relación alguna entre los cartujos y los dominicos del Convento de Santa Cruz la Real.

\footnotetext{
${ }^{35}$ Ibáñez y Mendoza, "El culto a la Santísima Virgen...”: 249. Et: Cfr. Baltasar Cuartero y Huerta, Versión que fray Lope Félix de Vega Carpio hizo del Himno de oro o Rosario rítmico por encargo del Padre Don Pedro Manuel Deza (Madrid: Tipografía de Rafael Carracín, 1935). [Facsímil de original sin fechar]
} 


\section{La Cofradía del Rosario de la Cartuja de Granada}

Tras las consideraciones previamente expuestas, en este último apartado crítico se va a proceder con el análisis propiamente dicho del documento titulado Libro de los Cofrades del Santísimo Rosario de Nuestra Señora, que se va escribiendo ${ }^{36}$. Este encabezado ya trasluce que se trata de un documento de carácter abierto que, fundamentalmente, encierra unas largas listas de nombres de padres, legos, donados, prebendarios y criados ${ }^{37}$ entre 1578 y 1796. Con todo, antes de entrar en materia, conviene clarificar que no se trata de un libro que permita al estudioso contrastar de forma sólida y continuada la evolución de ciertos aspectos de la historia de la Cartuja de Granada en el periodo de tiempo que comprende. Ello obedece, en primer lugar, a que los registros que contiene son altamente irregulares, con lagunas de información y saltos temporales que, en ciertos casos, superan con creces la media centuria. En segundo término, hay que sopesar el modo en que, con el paso de las décadas, la información que se proporciona es cada vez más sucinta, llegando al punto en que el libro deja de ser un reflejo de los cartujos que desean ser cofrades del rosario, para albergar las breves actas de nombramiento de capellán.

Más dificultosa aún resulta la labor de descifrar los datos correspondientes al año $1796^{38}$, los cuales se fueron escribiendo de forma salteada en los huecos en blanco que aparecían en las páginas iniciales, intermedias y finales. Por este motivo, nada más abrir el libro, aparece la primera parte de una extensa relación de los criados del monasterio, a los que no se les incluye con los monjes hasta, precisamente, finales del siglo XVIII. Esta anomalía se

\footnotetext{
${ }^{36}$ AHN, fondo Clero Secular-Regular, libro 3606, fols. 1r-55v.
}

${ }^{37}$ De acuerdo con la regla cartujana, como en toda orden monástica, existen distintos tipos de monjes. En primer lugar, están los padres o monjes de claustro, ordenados de presbíteros y dedicados por completo a la oración y el estudio. A continuación, figuran los legos o hermanos conversos, correspondiéndose con aquellos que realizan los trabajos serviles (llamados obediencias en la regla) que permiten el sustento de los padres. Después entrarían los donados, que son aquellos legos que han pedido entrar en la Orden con posterioridad a los 41 años, que es la edad de probación permitida y que, por tanto, no profesan los votos perpetuos. Por su parte, los prebendarios son sacerdotes que, pudiendo pertenecer a las filas de la Orden o no, son los encargados de cumplir con las mandas de misas y percibir los emolumentos vinculados a una prebenda adscrita a algún altar del monasterio. De otro lado, los novicios son considerados como hermanos conversos y, aquellos que permanecen en el monasterio para realizar una prueba de la vida cartujana previa a su ingreso o no en la Orden, son denominados como huéspedes. Al margen de toda normativa, se situarían los mayordomos y criados seglares, encargados de las relaciones del monasterio con el plano secular, así como de las labores propias de las explotaciones pertenecientes a la Cartuja. Cfr. Ordo Cartusiensis, Consuetudines Cartusiae (Grenoble: s.n., 1571).

${ }^{38}$ Esta fecha ha sido deducida por coincidir con la última acta que firma como prior dom Salvador de las Muelas. 
apoya en la tesis ya enunciada de Carlos Mensaque, siendo una clara muestra del modo en que la particular liturgia rosariana se va abandonando al plano de la religiosidad popular conforme avanza la Edad Moderna. De este modo, no será hasta fechas tan avanzadas y en este registro que es el último de todo el libro, cuando se unan las dos realidades rosarianas que hasta ese momento habían permanecido más o menos separadas en una vertiente de claro sabor popular $^{39}$.

Poco más de década y media antes de la constitución de la cofradía monástica, en 1562 y bajo el priorato de Pedro de San Sebastián (1559-1562), se configurará una pequeña capilla en el espacio de la portería del monasterio, en la que el padre procurador habría de cantar la misa dominical para los criados que trabajaban y vivían en la extensión de los dos cercados agrícolas que circundaban al cenobio. La composición de este pequeño espacio de culto fue posible gracias, precisamente, a la generosa capellanía fundada a este efecto por testamento de quien había sido mayordomo del monasterio, Rodrigo de Rivera ${ }^{40}$. No queda del todo clara la dedicación inicial de este espacio, aunque para el priorato de Bernardo de Castro (1574-1595) ya debía estar consagrado a la titularidad de la Virgen del Rosario, de la que existía un lienzo que presidía el testero. Conviene recordar que a este prior se debe la contundente reforma de la clausura del monasterio, tras las polémicas relajaciones que habían llevado al Capítulo General a intervenir su autonomía pocos años antes, entre 1568 y 1569. Además, será Bernardo de Castro el responsable de dar comienzo a numerosas iniciativas documentales y piadosas, pues a él se debe el inicio de páginas fundamentales para el conocimiento de la Cartuja de Granada, como el Libro del principio, fundación y prosecución $n^{41}$, o este Libro de los Cofrades del Santísimo Rosario.

Así pues, a este espacio de culto eucarístico y rosariano dedicado a los trabajadores seglares, habría que sumar los distintos altares de la clausura en que estuvo asentada la cofradía del rosario que, durante casi la totalidad de su devenir histórico, estuvo restringida a los padres, legos, donados y prebendarios

\footnotetext{
${ }^{39}$ Romero Mensaque, "El Rosario y sus cofradías...”: 622-623. Et: Antonio de la Chica Benavides, "Papel XL", Gazetilla curiosa, o semanero granadino, noticioso, y útil para el bien común, enero 7, 1765, Jubileo de las XL Horas (Parroquia de San Ildefonso).

${ }^{40}$ José A. Díaz Gómez, "El proyecto artístico de la Cartuja de Granada: revisión y nuevas aportaciones documentales en torno a su patrimonio y discurso iconográfico", en M. A. Rodríguez Miranda, I. Palomino Ruiz y J. A. Díaz Gómez (coords.), El legado inequívoco de una época. Homenaje al arquitecto Francisco Hurtado Izquierdo (Córdoba: Asociación "Hurtado Izquierdo", 2018), 103.

${ }^{41} \mathrm{Cfr}$. Francisco M. Torres Marín, ed., Libro del principio, fundaçion y proseçucion de la Cartuxa de Granada, (Granada: Universidad, 2007). Et: AHN, sección Clero Secular-Regular, libro 3611 "Libro del principio, fundaçion y proseçucion de la Cartuxa de Granada".
} 
del monasterio. De este modo, cuando Bernardo de Castro inicia el libro de cofrades en 1578, la corporación estaba asentada en el altar mayor del espacio que posteriormente se destinaría a Capítulo de legos y que, por entonces, hacía las veces de iglesia conventual, mientras se edificaba el espacio específico para este fin; la dedicación de este altar respondía a la Virgen de la Antigua, plasmada en el viejo lienzo traído al tiempo de la fundación en $1514^{42}$.

A partir de 1604, la titularidad mariana de este espacio cambiaría, sin duda motivada por la presencia del pintor Juan Sánchez Cotán, quien profesó como lego en ese año y permaneció en Granada hasta su muerte en $1627^{43}$. De su paleta saldría la extensa colección de nuevos lienzos que colmataría los nuevos retablos y dependencias del cenobio, de modo que el nuevo retablo de la primitiva iglesia había suplantado al viejo lienzo que presidía la cabecera, por la representación de la advocación titular del monasterio, la Virgen de la Asunción. Así parece que la renovación de este altar fue lo que motivó la realización de una nueva acta y nómina de cofrades en 1610, bajo el priorato de Jerónimo Blanco. No volverá a haber constancia documental de la cofradía hasta finales del siglo XVII cuando, para el año 1694, se estaba asentando en el altar de la Virgen de la Compasión, ubicado junto a las gradas de subida a la capilla mayor de la nueva iglesia, en el lado del Evangelio, en solemne ceremonia encabezada por el prior Francisco Ruiz de la Peñuela.

Tres años más tarde, el 2 de octubre de 1697, será cuando por vez primera dicho altar de la iglesia conventual aparezca con su dedicación definitiva a «Nuestra Señora del Rosario». Para dicha jornada, el sencillo altar anterior dedicado a la Virgen de la Compasión ${ }^{44}$, gozaba ya de nuevo ornato en cuyo centro se encontraba el magnífico lienzo de la Virgen del Rosario realizado por el genial Pedro Atanasio Bocanegra. Esta obra viene siendo datada en torno al año $1676^{45}$, coincidiendo con el resto de intervenciones del pintor granadino en el templo cartujo dentro de las postrimerías de su trayectoria (fig. 2). Por tanto, se trata de un cuadro preexistente en la colección de los cartujos que, finalmente, fue destinado a presidir el altar en que habría de estar asentada la cofradía del Rosario. Se trata de un espacio que, por entonces, debía presentar

${ }^{42}$ Díaz Gómez, "El proyecto artístico...", 78-81.

${ }^{43}$ Orozco Díaz, El pintor..., 108. Resulta llamativo que el nombre de Sánchez Cotán no figure en ningún momento entre la nómina de cofrades del rosario de Granada.

${ }^{44} \mathrm{La}$ forma en que estuvo representada esta advocación mariana se desconoce, por no aparecer una obra con dicho título en los inventarios posteriores. Véase, Díaz Gómez, "El proyecto artístico...", 81-133.

${ }^{45}$ Emilio Orozco Díaz, La Cartuja de Granada (Granada: Obra Cultural de la Caja de Ahorros, 1972), 36-43. 
un aspecto de gran sencillez dado que su enriquecimiento en madera sobredorada y mármoles de Lanjarón no se vería culminado hasta $1736^{46}$.

Por otra parte, volviendo sobre el culto desarrollado en la capilla de la portería, igualmente dedicada a la Virgen del Rosario, conviene remarcar el modo en que el prior Francisco de Bustamante, a la sazón responsable del diseño de los grandes proyectos artísticos de la Cartuja de Granada, supo aprovechar la presencia y el talento del escultor y pintor José Risueño Alconchel para, entre 1710 y 1712, encargarle la realización de una talla de dicha advocación mariana. De este modo, su finalidad habría sido la de presidir un nuevo altar configurado en la capilla de la portería, lo cual transmite ya la importancia del incremento del culto seglar en la Cartuja en torno al rosario, de manera que fue necesaria la realización de una escultura que obedeciese al formato devocional más común en los inicios del siglo XVIII. Sin duda, se trata de una talla pensada para mover a la piedad rosariana a los criados y mayordomos del monasterio (fig. 3$)^{47}$.

Así pues, una vez definidas las características, actividad y espacio de la cofradía del Rosario de la Cartuja, corresponde ahora centrar la atención en la estructura de su libro de cofrades, iniciado por dom Bernardo de Castro en 1578. No obstante, con posterioridad, se agregaron a las páginas iniciales otros documentos, lo cual puede conducir a una cierta confusión cronológica en la comprensión de la ordenación del libro. De hecho, como se indicaba anteriormente, en primer lugar aparece la relación de criados inscritos como cofrades en 1796. Se trata de una nómina interesante, pues permite comprobar los distintos oficios que requerían las labores desempeñadas en los dos vastos cercados del monasterio. De este modo, figuran con sus ayudantes el tahonero, el herrador, el maestro de cocina, el cocinero de los mozos de servicio, el chirrionero, el panadero, los porteros de los cercados, el bodeguero, el arriero, el cañero, el capataz de los mozos, el yesero, el albéitar, el espartero, el sastre, los guardas o los gañanes, así como otras dedicaciones de mayor rango, desempeñadas por personas respetables, como las del médico, el cirujano, el rasurero o el abogado.

A continuación, se insertan las bulas y decretos que regulan y reconocen la actividad de la cofradía, dispuestas asimismo al inicio del libro por prescripción contenida en los mismos documentos. De este modo, figuran la bula $\mathrm{Ad}$ perpetuam rei memoriam de Inocencio XI, con fecha de 25 de junio de 1679; la testificación de veracidad emitida, en calidad de notario, por el predicador general de los dominicos, fray Pedro Díaz de Cosío, el 7 de junio de 1681; y finalmente el rito de bendición del rosario y reconocimiento de indulgencias,

\footnotetext{
${ }^{46}$ Díaz Gómez, "El proyecto artístico...”, 117-118.

${ }^{47}$ Orozco Díaz, La Cartuja ..., 36-43. Et: Domingo Sánchez-Mesa Martín, José Risueño. Escultor y pintor granadino (1665-1732), (Granada: Universidad, 1972), 174-176.
} 
que el mismo Pedro Díaz ratificó el 31 de marzo de 1697. A todo ello, le sucede ya la documentación efectiva de principio del libro de cofrades, la cual se abre más de un siglo antes, como se apuntaba, en 1578 con el reconocimiento formal de la cofradía del Rosario de la Cartuja de Granada por decreto emitido asimismo por el predicador general de los dominicos en aquel momento, fray Serafín Cavalli, con reconocimiento del provincial castellano Francisco de Pereda. Además de lo ya consabido, una de las cláusulas más interesantes de este decreto es aquella que contempla la extensión de los beneficios espirituales de la cofradía a los profesos de la Cartuja de El Paular, de la cual dependió la iniciativa fundacional de la Cartuja de Granada entre 1513 y $1545^{48}$.

Al fin, aparece el registro de 11 de agosto de 1578, por el cual el prior fray Bernardo de Castro reconoce la autoridad que le confieren las bulas y decretos mencionados, con lo que procede a comenzar la nómina que da inicio al libro de cofrades de la Cartuja de Granada, a los que impone la obligación de rezar el rosario cada semana. Podría decirse que este prior fue quien más en serio tomó la utilidad de este registro pues, de su puño y letra, acomete inscripciones que no se van a volver a encontrar en todo el documento. De esta manera, en primer lugar se apunta a sí mismo, a sus padres, hermanos y abuelos, así como a monjes antiguos ya difuntos. Seguidamente y por orden de antigüedad, otros monjes de la casa hacen lo mismo, hasta llegar el turno a los legos, donados y prebendarios.

En la misma línea, el 25 de marzo de 1610, el prior Jerónimo Blanco abre una nueva lista de cofrades incluyendo en ella incluso a los huéspedes del monasterio, entendiendo por estos a aquellos aspirantes que se alojaban durante un tiempo en el mismo a fin de probar la forma de vida cartujana. De otro lado y aunque de forma ocasional se les identifica, no es común que se diferencie a los novicios como tales, ya que éstos suelen figurar entre la nómina de los hermanos legos, también denominados en el libro como frailes o conversos. Asimismo, será a partir del 2 de octubre de 1697 cuando, siendo prior Nicolás Ambrosio de Castro, se empiece a identificar al padre vicario dentro de la nómina de cofrades. Esta novedad es debida a que el prior comienza a derivar en esta figura las responsabilidades relativas a la cofradía, siendo el vicario también capellán de la misma por defecto.

A partir de las nóminas de 1709, con fray Francisco de Bustamante al frente de la comunidad, empiezan a figurar casos de cartujos que son eliminados de las listas con posterioridad por haber dejado la Orden. También aparecen tratamientos distintivos para con aquellos monjes de cierta antigüedad que han sido priores o vicarios con anterioridad, a los que se refiere como "venera-

${ }^{48}$ Torres Marín, Libro del principio..., 5-35. Et: Díaz Gómez, “La Cartuja de Granada...”: 8-29. 
bles", mientras que son "carísimos" aquellos que poseen sangre nobiliaria. Se trata de una circunstancia que se hace llamativa, puesto que este tipo de distinciones resultan contrarias a los usos cartujanos, que por lo general prefieren rechazar toda dignidad eclesiástica y que sólo suelen admitir como mención especial aquella del laudabiliter vixit, que acompaña en las actas necrológicas al nombre del cartujo que vivió de forma ejemplar, previo consenso absoluto del Capítulo ${ }^{49}$. Con todo, no deja de presentarse como una anécdota que pone de manifiesto el modo en que, en determinados momentos de su historia, se experimentó una mayor o menor relajación de las costumbres del monasterio.

Por lo demás, como se señalaba al comienzo de este apartado, las relaciones de monjes y criados inscritas en el libro de cofrades no permiten contrastar la nómina de integrantes del monasterio de forma fiel a lo largo de su historia, ya que igualmente es común la cortesía de incluir en el libro a monjes de otras cartujas. Ello se aprecia con nitidez en listados como el de 1738, en que por única vez aparecen apellidos extraños a la comunidad de Granada, como Mahony o Mazquiarán. Ya en la nómina posterior a 1796 se especificará con mayor claridad estas casuísticas con ciertos monjes, como los padres Silvestre Rico y José Obeso, de los que se aclara que son profesos de la Cartuja de Sevilla. También figura el padre Antonio García Herreros, profeso de Aniago. Se trata de monjes que recibían esta deferencia por ser visitadores que, en determinado momento, pasaron por la Cartuja de Granada. Por tanto, no se puede detallar aquí con precisión la integración de la comunidad por no conocer en profundidad las identidades, aunque sí que hay que considerar que la mayor parte de los nombres que aparecen en las relaciones de cofrades son profesos granadinos. A continuación, se facilitará una tabla con la que se pretende simplificar la comprensión de las cifras que se manejan en el análisis del documento:

\begin{tabular}{|l|l|c|c|c|c|}
\hline Año & \multicolumn{1}{|c|}{ Prior } & Padres & Conversos & Donados & Huéspedes \\
\hline $\mathbf{1 5 7 8}$ & Bernardo de Castro & $14+2^{50}$ & 7 & 0 & 0 \\
\hline $\mathbf{1 6 1 0}$ & Jerónimo Blanco & 37 & $25+1^{51}$ & 13 & $5^{52}$ \\
\hline $\mathbf{1 6 9 4}$ & Fco. Ruiz de Peñuela & 14 & 7 & 5 & 1 \\
\hline $\mathbf{1 6 9 5}$ & José de Cheverri & 3 & 1 & 3 & 1 \\
\hline $\mathbf{1 6 9 7}$ & Nicolás A. de Castro & 27 & 10 & 19 & $6^{53}$ \\
\hline
\end{tabular}

\footnotetext{
${ }^{49}$ Roig, Diálogos ..., 132-134.

${ }^{50} 14$ padres a los que se suman dos prebendarios.

${ }^{51} 25$ conversos a los que se añade uno más como novicio. No volverá a aparecer esta diferenciación.

${ }^{52}$ Tres padres, un converso y un donado.

${ }^{53}$ Todos ellos eran padres.
} 


\begin{tabular}{|l|l|l|l|l|l|}
\hline $\mathbf{1 7 0 9}$ & Fco. de Bustamante & 32 & 14 & 8 & 0 \\
\hline $\mathbf{1 7 2 0}$ & Fco. de Ugarte & 24 & 15 & 6 & 0 \\
\hline $\mathbf{1 7 2 3}$ & José de San Bruno & 30 & 17 & 6 & $1^{54}$ \\
\hline $\mathbf{1 7 2 9}$ & Juan B de la Hoz & 19 & 20 & 2 & $1^{55}$ \\
\hline $\mathbf{1 7 3 0}$ & Antonio Corrochano & 26 & 20 & 4 & 0 \\
\hline $\mathbf{1 7 3 6}$ & Nuño de Villavicencio & 28 & 21 & 7 & 0 \\
\hline $\mathbf{1 7 3 8}$ & Juan Antonio Martín & 31 & 21 & 8 & $1^{56}$ \\
\hline $\mathbf{1 7 3 9}$ & & 35 & 0 & 0 & 0 \\
\hline $\mathbf{1 7 9 6}$ & Salvador de las Muelas & 46 & 35 & 30 & 0 \\
\hline
\end{tabular}

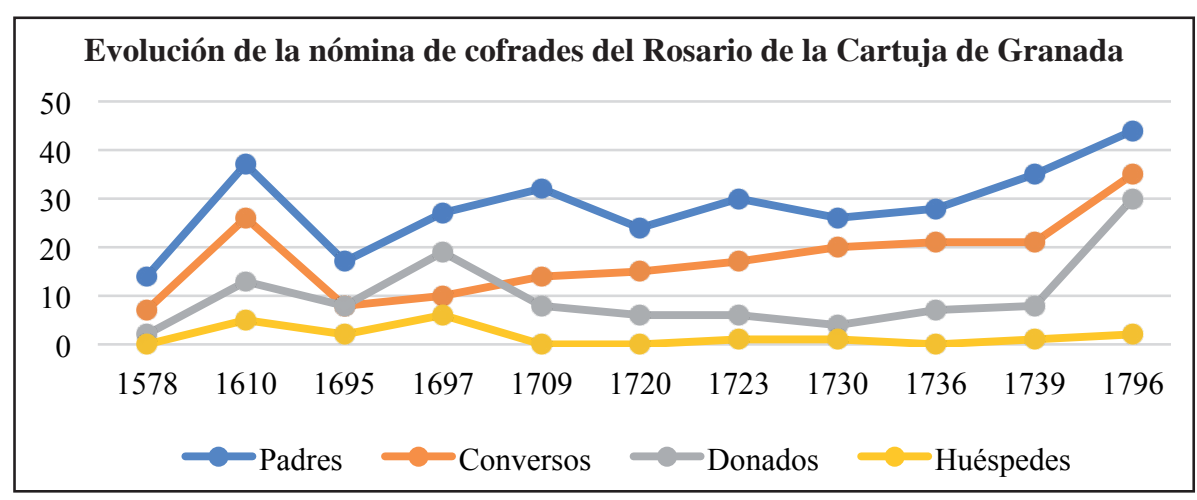

Exceptuando los registros de 1695 y 1739, que pueden considerarse meras ampliaciones de aquellos otros que les preceden, en el resto de listados puede apreciarse la irregularidad de las inscripciones, sobre cuyas causas no se va a volver a insistir, y que hace poco útil el establecimiento de cualquier promedio, ya que no hubo nunca un criterio uniforme para la confección de dichos registros. Resulta claro que unos pocos priores, al inicio de su priorato, se interesaron por elaborar nuevas listas, en unos casos, o por completar las anteriores, en otros. Con todo, cuando se dan las ampliaciones de los registros, unos nombres de listas anteriores se repiten, mientras que otros no, al margen de las nuevas inscripciones. Ello por no mencionar los casos en que, en una misma nómina, aparece en dos ocasiones un mismo monje, lo que se produce también en la relación de los criados de 1796, cuya cifra (eludiendo repeticiones) asciende a 256 operarios del monasterio. Por tanto, se puede concluir que este libro de cofrades era un documento piadoso apetecido por los monjes y

\footnotetext{
${ }^{54}$ Converso.

${ }^{55}$ Padre.

${ }^{56}$ Padre.
} 
su entorno, aunque no interesante ni importante en la administración del monasterio, por lo que se pone poco esmero en su elaboración. De hecho, como se anunciaba a priori, entre 1738 y 1796, se prescinde ya de hacer listado y el registro se limita a la confirmación del padre vicario de turno como capellán de la cofradía por parte del prior correspondiente, del modo en que reflejan los siguientes datos:

\begin{tabular}{|l|l|l|}
\hline Año & \multicolumn{1}{|c|}{ Prior } & \multicolumn{1}{|c|}{ Vicario } \\
\hline $\mathbf{1 7 4 2}$ & Francisco Pinto & José Arroyo \\
\hline $\mathbf{1 7 4 6}$ & & Juan de Guzmán \\
\hline $\mathbf{1 7 4 7}$ & \multirow{2}{*}{ José Arroyo } & Antonio Guardia \\
\hline $\mathbf{1 7 5 2}$ & Tomás Javier de Esparza \\
\hline $\mathbf{1 7 5 2}$ & Tomás Javier de Esparza & José Vázquez \\
\hline $\mathbf{1 7 5 4}$ & Francisco Pinto & José Recarte \\
\hline $\mathbf{1 7 5 5}$ & & José Vázquez \\
\hline $\mathbf{1 7 5 8}$ & & Manuel de Armenteros \\
\hline $\mathbf{1 7 5 9}$ & Gaspar Pérez & Pedro Loranca \\
\hline $\mathbf{1 7 6 2}$ & & Fernando Rodríguez \\
\hline $\mathbf{1 7 7 1}$ & Manuel de Aldea & Fernando Rodríguez \\
\hline $\mathbf{1 7 7 2}$ & Martín Nieto \\
\hline $\mathbf{1 7 8 3}$ & Domingo Lastiri & Pedro Imirizaldu \\
\hline $\mathbf{1 7 9 2}$ & Lope Núñez de Mendoza & Fernando Arias Gago \\
\hline $\mathbf{1 7 9 3}$ & Pedro Imirizaldu \\
\hline $\mathbf{1 7 9 6}$ & Salvador de las Muelas & Juan Francisco Gómez Plaza \\
\hline
\end{tabular}

\section{Conclusiones}

El Libro de los cofrades del Santísimo Rosario de la Cartuja de Granada se constituye, en última instancia, en un sencillo e irregular documento histórico que posibilita la comprensión de un fenómeno atípico, como lo es la conformación de una cofradía monástica en la clausura del cenobio iliberitano. Se trata de un hecho singular, que únicamente compartieron otras tres cartujas más dentro de los dominios hispánicos, poniendo de relieve la tensión entre las propias costumbres cartujanas y el influjo imparable de las fórmulas dominicas en torno a una seña de identidad fundamental que ambas congregaciones se arrogan, como es la devoción del rosario. 
Este ejercicio ha cumplido históricamente su función creciente como salterio de los humildes, en sustitución del salterio canónico recitado en los coros de los instruidos. Tanto es así que, dentro de la propia rigidez cartujana, se puede apreciar una evolución afable en un plano de paulatina apertura al terreno seglar, aquí representado por los criados y mayordomos del monasterio, cuya participación será plena al iniciarse el siglo XVIII. Si bien el influjo de la religiosidad popular fue capaz de moldear artísticamente ciertos espacios del monasterio, dentro y fuera de la clausura, también aquellos monjes cultivados se manifestarán como receptáculos del salterio de los sencillos, en tanto que pobres de espíritu partícipes de unos miedos ultraterrenos que comparten con el resto de la humanidad. El rosario nace y evoluciona como un mecanismo más para alcanzar la salvación del alma, a pesar de las faltas particulares, de las relajaciones en el cumplimiento de la norma y de todas aquellas otras circunstancias que se desprenden de la puesta en contexto de extensas y aparentemente opacas listas de nombres cartujos y cartujanos.

\section{Bibliografía}

Alonso Getino, Luis G. Origen del Rosario y leyendas castellanas del siglo XIII sobre Santo Domingo de Guzmán, Vergara, Tipografía del Santísimo Rosario, 1925.

Anónimo cartujo. El Santo Rosario en la Cartuja, Salzburg, Universität, Institut fur Anglistik und Amerikanistik, 1983.

Antequera Becerra, Luis. El cristianismo desvelado. Respuestas a las 103 preguntas más frecuentes sobre el cristianismo, Madrid, EDAF, 2007.

Barceló de Torres, E. y Ruiqz Gómez, L. La recuperación de El Paular, Madrid, Ministerio de Educación, Cultura y Deporte - Subdirección General del IPCE, 2013.

Barile, Riccardo. Il Rosario, Salterio della Vergine, Bolonia, Edizioni Dehoniane, 1990.

Cantera Montenegro, S. y Torrego Casado, A. (eds.), Contemplaciones sobre el rosario de Nuestra Señora, Salzburg, Universität, Institut fur Anglistik und Amerikanistik, 2002.

Chéry, Marcelin. La Théologie du Saint Rosaire, París, Poussielgue, 1869.

- Histoire générale du Rosaire et de sa confrérie, París, Poussielge, 1869.

Cuartero y Huerta, Baltasar. Versión que fray Lope Félix de Vega Carpio hizo del Himno de oro o Rosario rítmico por encargo del Padre Don Pedro Manuel Deza, Madrid, Tipografía de Rafael Carracín, 1935. [Facsímil de original sin fechar] 
Delgado López, Félix. "Juan de Baeza y las pinturas de Vicente Carducho en la cartuja del Paular", Locus amoenus 4 (1998-1999), 185-200.

Díaz Gómez, José A. "La Cartuja de la Asunción (Granada): datos inéditos para la revisión de su historia", Archivo Teológico Granadino 82 (2019), 7-68.

- "El proyecto artístico de la Cartuja de Granada: revisión y nuevas aportaciones documentales en torno a su patrimonio y discurso iconográfico". En Rodríguez Miranda, M. A., Palomino Ruiz, I. y Díaz Gómez, J. A. (coords.) El legado inequívoco de una época. Homenaje al arquitecto Francisco Hurtado Izquierdo, 76-136, Córdoba, Asociación "Hurtado Izquierdo", 2018.

Duval, André. "Rosaire". En: Viller, M., Cavallera, F. y Gibert, J., Dictionnaire du Spiritualité, Ascetique et Mistique, vol. XIII, 937-980, Paris, Beauchesne, 1988.

Ibáñez, J. y Mendoza, F. "El culto a la Santísima Virgen en la Cartuja. El Santo Rosario", Scripta de María 1 (1978), 157-269.

Linage Conde, Antonio. "Tentativas cartujanas en la América Española", Hispania Sacra 80 (1987), 405-431.

López-Guadalupe Muñoz, Miguel L. "Expansión de las cofradías del Rosario en la diócesis de Granada en la época moderna". En: Paz Castaño, H. y Romero Mensaque, C. J. (coords.), Congreso Internacional del Rosario. Actas, 379-389, Sevilla, RD Editores, 2004.

Mayo Escudero, Juan. Expansión y organización de la Orden de la Cartuja, Salzburgo, Universität, Institut fur Anglistik und Amerikanistik, 2002.

Orden de Predicadores, Sumario de las indulgencias concedidas a los cofrades del Santísimo Rosario y Dulce Nombre de Jesús, con otras comunes a todos los fieles, Madrid, Imprenta y Fundición de D.E. Aguado, 1845.

Ordo Cartusiensis, Consuetudines Cartusiae, Grenoble, s.n., 1571.

Orozco Díaz, Emilio. El pintor fray Juan Sánchez Cotán, Granada, Universidad - Diputación Provincial, 1993.

- La Cartuja de Granada, Granada, Obra Cultural de la Caja de Ahorros, 1972.

Romero Mensaque, Carlos J. "Los comienzos del fenómeno rosariano en la España moderna. La etapa fundacional: siglos XV y XVI", Hispania Sacra LXVI, Extra II (2014), 243-278.

- "El Rosario y sus cofradías en Andalucía. Una aproximación histórica", Hispania Sacra LXII, 126 (2010): 621-659.

Sánchez-Mesa Martín, Domingo. José Risueño. Escultor y pintor granadino (1665-1732), Granada, Universidad, 1972.

Savonarola, Girolamo. "Esposizione sopra l'orazione della Vergine", Marian Library Studies 10 (1978), 81-105.

Torres Marín, Francisco M. (ed.). Libro del principio, fundaçion y proseçucion de la Cartuxa de Granada, Granada, Universidad, 2007. 


\section{Anexo: transcripción documental}

Libro de los Cofrades del Santísimo Rosario de Nuestra Señora, que se va escribiendo.

Está también en este libro la concesión del Reverendísimo Padre General de la Sagrada Orden de Predicadores a esta Casa, y a la de Nuestra Madre la Cartuja del Paular, para la Institución de la Confradía del Santísimo Rosario de Nuestra Señora.

L.B. $n^{\circ} 42$.

- [Fol. 1r] Cecilio de Huertas.

- Bartolomé de la Fuente, está en el horno.

- Antonio de Torres, tahonero.

- Cristóbal Fernández, en el horno.

- Pedro Martín Lázaro.

- Martín Gómez.

- Antonio Luján, herrador.

- Lorenzo Berbel, maestro de cocina, dice está sentado en los libros de Santo Domingo.

- Fernando Pacheco, está en la cocina.

- Manuel Martín, cocinero de los mozos.

- Antonio de la Fuente.

- Juan Vázquez, chirrionero.

- Francisco Hernández, maestro de panadero.

- Nicolás de Osma.

- Manuel Méndez, portero del cercado de arriba.

- Antonio Milán, gañán.

- Nicolás de Escalona.

- Nicolás Gómez.

- Juan Gómez.

- Agustín Luján.

- Francisco Martín Lázaro, está con el borriquillo.

- Antonio de la Hoz.
- Manuel Torivio López, es gañán.

- Pedro Curtidor, bodeguero.

- Juan de San Pedro, está en la cocina.

- Felipe de Coria, está en el cercado de abajo.

- [Fol. 1v] Manuel de Arroyo, arriero.

- Fernando Muñoz, gañán.

- Pedro García, capataz.

- Antonio Martín, el cañero.

- Hipólito Martín, portero de abajo.

- Miguel González.

- Pedro Ruiz, yesero.

- Don Francisco Vallejo, médico.

- Don Francisco de Atienza, cirujano.

- Don Damián de Campos, rasurero.

- Don Juan Revertí, abogado.

- Don Cristóbal de Espinosa.

- Don Mateo Herrero.

- Don Sebastián Bravo Ronquillo.

- Don Francisco Javier Herranz.

- Joseph Naranjo, albéitar.

- Alonso Nucete, gañán.

- Juan Martín, está en las cañerías.

- Blas Obispo.

- Manuel Riesco, es cocinero.

- Damián Vidal, espartero.

- Pedro Arroyo, guarda del Chorro de Oznar. ${ }^{57}$

- Antonio de Hita.

\footnotetext{
${ }^{57}$ Ramal de la acequia de Aynadamar.
} 
[Fol.2r]

INNOCENTIUS PAPA XI. AD PERPETUAM rei memoriam.

Exponi nobis nuper fecit dilectus filius Antonius de Monroy, Magister generalis ordinis Fratrum Prædicatorum, quod licet multæ in dicti ordinis, aliisque ecclesiis, seu oratoriis existant confraternitates utriusque sexus Christifidelium sub titulo sanctissimi Rosarii, quæ suas functiones ad instar similium confraternitatum obeunt, multaque pietatis, et christianæ charitatis opera exercent, de aliquarum tamen ex illis canonica ab initio institutione forsan non constat, et in aliarum erectionibus, et institutionibus præscripta per constitutionem felicis recordationis Clementis Papa VIII prædecesoris nostri, quæ incipit: quaecumque a Sede Apostolica, etc. die VII decembris MDCLV editam; forsan servata non fuerunt, et aliæ ante emanatam constitutionem huiusmodi erectæ, et institutæ novas erectionum, et institutionum huiusmodi, ac communicationis indulgentiarum, facultatum, et privilegiorum literas intra tempus ab eadem constitutione praefixum, seu etiam postea impetrasse minime reperiuntur. Nobis propterea dictus Antonius Magister generalis humiliter supplicari fecit, ut in præmissis opportune providere, et ut infra indulgere de benignitate apostolica dignaremur.

Nos igitur ipsum Antonium Magistrum generalem specialis favore gratiæ prosequi volentes, et a quibusvis excommunicationis, suspensionis, et interdictis, aliisque ecclesiasticis sententiis, censuris, et pœnis, a iure, vel ab homine quavis occasione, vel causa latis, si quibus quomodolibet innodatus existit ad effectum præsentium duntaxat consequendum harum serie absolventes, et absolutum fore censentes, huiusmodi supplicationibus inclinati, omnes, et singulas confraternitates praedictas sub titulo Sanctissimi Rosarii in quibusvis tam dicti ordinis, quam aliis ecclesiis, seu oratoriis, ubicumque locorum de præsenti existentes, tametsi de earum canonica ab initio erectione, et institutione non appareat, nec ipsas confraternitates novas erectionum, et institutionum, seu communicationis indulgentiarum, facultatum, et privilegiorum huiusmodi literas infra tempus a præfata Clementis prædecessoris constitutione præfixum obtinuisse reperiatur, nec in earum erectionibus, et institutionibus præscripta per eamdem constitutionem servata fuerint, auctoritate Apostolica, tenore presentium, confirmamus, et validamus, easque in statu valido esse, et fore decernimus, et declaramus, in omnibus, et per omnia, perinde ac si illas omnes, et singulas ab ipso initio canonice erectas, et institutas fuisse, novasque erectiones, et institutiones suo tempore iuxta formam memoratce constitutionis Clementis pradecessoris obtinuisse constaret, et in reliquis eiusdem constitutionis forma in illarum erectionibus, et institutionibus respective servata fuisset, omnesque, et singulos iuris, et facti defectus, qui propter præmissa desuper quodomolibet intervenerunt, 
seu intervenisse dici, censeri, vel protendi possent, supplemus, et sanamus. Et quatenus opus sit, ipsas confraternitates omnes, et singulas (servata tamen cateroquin constitutionum, et decretorum huius Sancta Sedis, prasertim circa distantiam locorum in erectione confraternitatum similis instituti servandam emanatorum forma, et dispositione) de novo erigimus, et instituimus.

Ceterum in erectione, et institutione similium confraternitatum de cetero faciendis, formam in supradicta Clementis prædecessoris constitutione præscriptam [Fol.2v] adamussim servari volumus, alioquin erectiones, et institutiones huiusmodi nullius omnino sint roboris, et momenti.

Decernentes easdem præsentes literas firmas, validas, et efficaces existere, et fore, suosque plenarios, et integros effectus sortiri, er obtinere, ac illis ad quos spectat, et pro tempore quandocunque spectabit in omnibus, et per omnia plenissime suffragari, et ab eis respective inviolabiliter observari, sicque, in præmissis per quoscunque iudices ordinarios, et delegatos, etiam causarum Palatii apostolici auditores iudicari, et definiri debere, ac irritum, et inane, si secus super his a quoquam, quavis auctoritate, scienter, vel ignoranter contigerit attentari.

Non obstantibus præmissis, ac quatenus opus sit, nostra, et Cancellariæ Apostolicæ regula de non concedendis indulgentiis ad instar, ac prædicta Clementis prædecessoris, aliisque constitutionibus, et ordinationibus, apostolicis, necnon quibusvis etiam iuramento, confirmatione apostolica, vel quavis firmitate alia roboratis, statutis, et consuetudinibus, privilegiis quoque, indultis, et literis apostolicis, in contrarium præmissorum quomodolibet concessis, confirmatis, et innovatis.

Quibus omnibus, et singulis, illorum tenores præsentibus pro plene, et sufficienter expressis, et de verbo ad verbum, insertis habentes, illis alias in suo robore permansuris, ad præmissorum effectum hac vice duntaxat specialiter, et expresse derogamus, ceterisque contrariis quibuscunque.

Volumus autem, ut earundem præsentium literarum trasumptis, seu exemplis etiam impressis manu alicuius notarii publici subscriptis, et sigillo personæ in ecclesiastica dignitate constitutæ munitis, eadem prorsus fides ubique locorum, tam in iudicio, quam extra illud habeatur, quæ haberetur ipsis præsentibus, si forent exhibitæ, vel ostensæ.

Datum Romæ apud Sanctum Petrum sub annulo Piscatoris die XV Iunii MDCLXXIX, Pontificatus nostril anno tertio. I.G. Slusius.

Yo Fray Pedro Díaz de Cosío, Predicador general de la Orden de Predicadores, testifico, y doy fe in verbo Sacerdotis, en vez de Notario, de las cosas siguientes respectivamente. 
Lo primero, que la Bula referida confirmativa de las Cofradías del Santísimo Rosario, con su autenticación al pie de siete Bulas Apostólicas, como abajo se dirá: está fielmente copiada, y concuerda con su original, que queda en mi poder.

Y asimismo certifico, y doy fe, que junto con la referida Bula del Rosario, y las demás, y con la misma autenticación de Notario, y sello: de molde está otra Bula (semejante a esta) por la cual el mismo Santísimo Padre Inocencio Undécimo ha confirmado, y aprobado todas las Cofradías del Santísimo Nombre de Jesús, sive iuramentorum, sitas en todas las Iglesias de nuestra Religión de Santo Domingo, supliendo cualesquier defectos que hayan tenido en sus Fundaciones, y aunque las tales Fundaciones no parezcan; y que siendo necesario, su Santidad dice las funda por la presente Bula, que fue fecha en Roma a 18 de abril de 1678 .

Y más está, so la mesma autenticación, otra Bula, por la cual concedió su Santidad el mesmo Pontífice Inocencio Undécimo a todos los Cofrades, y Cofradas del Santísimo Rosario facultad, y que puedan aplicar todas, y cualesquier Indulgencias del Rosario a ellos concedidas, y que ganaren, por las ánimas del [Fol.3r] Purgatorio per modum suffragii, que fue fecha en Roma a 15 de junio de 1679.

\section{Testificación del Notario}

Hae septem Bullae concordant suis originalibus, a me inspectis de verbo ad verbum: demptis hisce mendis, nempe, in prima ut prones: in secunda deest omnino, Semunitis: in tertia Confratribus pro Confraternitatibus: in quarta deest Fidelium, et nomine. Et in fidem manu propria subseripsi. Romae die 7 Junii millesimi sexcentesimi octuagesimi primi.

In testimonium veritatis + signum appono.

Laurentius Álvarez Cantos.

Notarius publicus Apostolicus.

Y asimismo certifico, y doy fe, que tengo en mi poder otra Bula del referido Santísimo Papa Inocencio Undécimo, firmada, signada, testificada, y sellada de Notario Apostólico, su fecha en Roma a 31 de julio de 1679, por la cual su Santidad ha confirmado, y renovado las Indulgencias del Rosario, contenidas en el Sumario de todas ellas, que por mandado de la Santa Silla Apostólica fue reconocido, y aprobado por la Sacra Congregación en 11 de julio de 1679, como su Santidad lo dice en dicha su Bula.

Y presentado de nuevo a su Santidad el dicho Sumario, está inserto en la referida su Bula, y confirmado como en él se contenía. 
Y asimismo certifico, y doy fe, que esta dicha Bula con dicho Compendio contenido en ella, traducida en Castellano, fue presentada en el Supremo Consejo de la Santa Cruzada, de quien salió aprobada, y mandadas publicar las Indulgencias del Santísimo Rosario en ella contenidas, por testimonio de su Secretario de Cámara, Agustín Rodríguez de la Gala, a 26 de enero de 1680, como todo consta del testimonio que de ello dio Domingo de Mendieta, Notario Apostólico de la Nunciatura de España, en Madrid a 3 de octubre de 1682 años.

Y asimismo certifico, y doy fe, que nuestro muy Reverendo Padre Provincial el Maestro Fray Domingo Pérez, habiendo visto, y considerado las Bulas, y Breves auténticos referidos, que quedan en mi poder, me ha mandado su Paternidad muy Reverenda por escrito, y en mérito de santa obediencia, que lo haga imprimir, y certificar (como va referido) y que remita copias las más que pudiere a toda la Provincia. Para que los Padres Priores procuren ingerir una en cada libro de la Cofradía de cada lugar de su distrito, donde probablemente estuviere fundada. Y que los señores Curas, y Cofrades de ellas, vean todos, y cada uno, cómo su Cofradía está confirmada por la Santa Sede Apostólica para siempre jamás. Y que todos vean y sepan la seguridad, y firmeza perpetua de las Indulgencias del Santísimo Rosario. Y que en adelante solo necesitan de tener, cada una, su Abad nombrado por el Padre Prior del Convento más cercano, para su gobierno. Y para escribir los Cofrades que de nuevo entraren. Y que (a su tiempo) haga llevar el libro, para que dicho Padre Prior los reciba, y confirme, y nombre Abad, si hubiere vacado.

$Y$ asimismo certifico, que las dos cosas siguientes, son copiadas del Breviario de la [Fol.3v] Orden de Predicadores, y se añaden aquí, para que los señores Abades de las Cofradías del Rosario, nuestros Tenientes, no las omitan por falta de advertencia, y la forma de ellas.

\section{ABSOLUTIO, SEU INDULGENTIAE IMPARTIENDAE}

Confratribus Rosarii in articulo mortis.

Dicto, confiteor si potest infirmus, et si non? Alii pro eo: dicat Pater Spititualis misereatur tui, etc. indulgentiam, etc. Dominus Noster Iesus Christus Filius Dei vivi, qui Beato Petro Apostolo suo, dedit potestatem ligandi, atque solvendi, per suam piissimam misericordiam, recipiat confessionem tuam, et remittat tibi Omnia peccata tua, quaecumque, et quomodocumque in toto vita tuae cursu commisisti, de quibus corde contritus, et ore confessus es, restituens tibi Stolam primam quam in baptismate recepisti: et per Indulgentiam plenariam, a Summis Pontificibus Innocentio Octavo, et Pio Quinto, Confra- 
tribus Sanctissimi Rosarii in articulo mortis constitutis concessam; liberet te a praesentis, ac futura vitae poenis, dignetur Cruciatus Purgatorii remittere, portas, inferi claudere, Paradisi Ianuam aperire, teque ad gaudia sempiterna perducere, per sacratissima suae vitae, Passionis, et glorificationis Mysteria Sanctissimo Rosario comprehenda. Qui cum Patre, et Spiritu Sancto Deus unus, vivit, et regnat in saecula saeculorum, Amen.

El Papa Clemente Nono, in articulo mortis: pidió, y consiguió esta absolución mediante el Padre General de Santo Domingo: consta por testimonio de Notario Apostólico, que estaba presente en Roma. Y el Papa Clemente Décimo, en el mismo artículo, pidió, y consiguió lo mismo, como lo certifica el señor Arzobispo Rocabertí, que se la otorgó, como Maestro General que entonces era, y al presente es Inquisidor general.

\section{BENEDICTIO ROSARIORUM}

Sacerdos cum Stola, dicat. Adiutorium nostrum in nomine, etc. qui fecit, etc. Domine exaudi, etc. Dominus, etc. et cum Spiritu, etc.

Omnipotens, et misericors Deus, qui propter eximiam charitatem tuam, qua dilexisti nos, Filium tuum unigenitum Dominum nostrum Iesum Christum de coelis in terram descendere, et de Beatissimae Virginis Mariae Dominae nostrae Utero Sacratissimo, Angelo nuntiante, carnem suscipere voluisti, ut nos eriperes de potestate diaboli, obsecramus inmmensam clementiam tuam, ut haec signa Rosarii, in honorem, et laudem, eiusdem Genitricis Filii tui, ab Ecclesia tua Fideli dicata bene+dicas, et sanctifices, eiusque tantam infundas virtutem Spiritus Sancti, ut quicumque horum quodlibet secum portaverit, atque in domo sua reverenter tenuerit; ab omni hoste visibili, et invisibili, Semper, et ubique, in hoc saeculo liberetur, et in exitu suo ab ipsa Beatissima Virgine Maria Dei Genetriciae, tibi plenus bonis operibus praesentari mereatur. Per eundem Dominum, etc. Deinde Aspergantur aqua benedicta.

En testimonio de verdad de todo lo referido (respectivamente) y en vez de Notario lo firmé en San Pablo de Burgos (esta cuarta impresión) a 31 de marzo de 1697.

X Fray Pedro Díaz de Cosío.

[Fol.4r] Nombramiento de Capellán, fol. 15.

Asiento de los Padres Monjes, folio 14.

Asiento de los Religiosos Conversos, y Donados, folios 24 y 25.

Asiento de los Criados del Monasterio, folio 36. 
[Fol.4v: En blanco]

[Fol.5r. H.1]

Nos Fr. Seraphis Cavalli, sacra Theologia professor ac totis ordinis Predicatoris, humilis Generalis Magister et servuus. Christiana charitas, et scbn. que fungimur religionis ministerium quos de sacra religione nra. pie, et egregie meritos novit, benigno amore, piisque viseribus suscipit, adeaque charitatis officia recipit, quae imprimis srib., eximiaque caharitate, et excellenti religione, fide, ac pietate coniunctis pio iure rebentur. Quod cum religiosissima RR. PP. Religió sacra, piaque Carthusiansius singulari nos, universumque ordinem nrm. Predieque, amore, et dilectione gratissima prosequatur, suma. debemus observantia, parique dilectionis eos affectu suspicere, diligere, ac prosequi. Quare nre. in tantos tamque religiosos PP. Nobis obmos., et charmos. in D.J.X. dilecionis, et observantia testimonium pium, fideleque, hars serie $n$. autsote oficiis universos, et singulos RR. Patres, \& fratres Vllis. admosu. ac religiosissimi Convs. Carthusien. urbis suis Granaten. extra muros, simul Donatos, ac praebendarios tam presentes, que futuros admittimus, recipimusque ad oia., \& singula totis ordinis nostri Beneficia tam frum., que sororum per Universum orben difussarum, ut sitis participes oium. missarum, Divinorum sacrificiorum, ieiniorum, abstinentiarum, disciplinarum, vigilarum, lectionum, studiorum, praedicationii, ac peregrinationum, confesorumque bonorum, ac meritorium quae per universum orbem fribs., ac sororibus nostris Divina bonitas concesserit operari, quemadmodum speciales fratres nostri ad beneficia ordis. admisti, gaudere solent, ac debent. Insuper in scbn., ac Venerabile Beatissima Virginis ed Domina D.N. Deigenetricis Maria pium obsequium, uberioremque Destionem, honorem, et laudemus recipimus RR. YY. PP ac reverentias, futurosque Patres, et fratres, Donatos, ac praebendarios tam presentes que futuros ad sctam. Confraternitatem Ssmi. Rosarii Bma. Virgis. \& Dna. N. facultatem facientes R.P. Priori pro tempore recipiendi seribendique confratres universos, et singulos prenominatos ad pefata. tam societatem Rosarii in libro ad hoc specialiter reputato, sacellum, et altare tam in ecclesía [Fol.5v. H.1] \& templo, que in cellis, ubi pro more sacri ordinis Divinum Officium celebratur, cultusque exercetur, eius nomini \& invocationi erigere, et dedicare, instituereque; Rosaria, et coronullas benedicere, sacra eisdem sodalitatis mysteria exponere, atque (ojo) Omnia et singula faere in pdo. suo conusu. sacro, ac Venerli. pro suis fratribus religiosis, ac caeteris nominatis, quae per nros. fres. In nris. lecliis. ad hoc deputatos fieri solent, et possunt. Atqui qm. quae pro Charitate fiunt, sina aemulatione, sed magis ad proximorus sunt edificationem, ad instantiam, et devotas preces RR. PP. Prioris et Patrum pefati. Cons. Sacri Carthusian. Granatensi, eadem prorsus dilectione, iisdemque Charitatis 
visceribus recipimus ad nostrum fraternitatem specialem universis, et singulos religiosos Pres. utque. RR. Fres., Dnato, ac praebendarios tan presentes, que futuros. Inesiti ac observantiis Cons. Carthusiani del Paular ad Segobiam, admittentes eos ad oia., \& singular totius nostril ordinisi beneficia, et gratias, quemadmodum veros, ac legitimos ords. fres., benefactores, et amicos. Ad hace, ut sacram Ssmi. Rosarii devotionem promoveamus, recipimus eosdem ad Sctam., Devotamque ipsius sacri Rosarii sodalitatem, et confraternitatem, eamdem prorsus facultate. dantes R.P. Priori pro tempore eiusdem convs. del Paular ad confers. vlg. Prenominatos tam presentes, que futuros recipiendum, in speciali libro scribendum, altaria etts. erigendum, instituendum; Rosaria bendicendum, mysteria sacra exponendum, aliosque actus neccesarios exercendum, quemadmodum R.P. Priori Granatensi concessimus Annunciantes ipsis, universis, et singulis, et adeo ipsismodo ita per nos ad mam. societatem spiritualem receptis, et admissis plenariam oium. decors pctors. indulgentiam per Sanctam Sede Appostolicam benigna largitate fuisse concessam semel in vita, et semel in morte. Ad quae oia. religiosa nos charitate, singulari dilectionis affectu, atque ex intimo cordis amore comendantes nos ipsum, sacriique nostram ordinem suis sctis., piis, et ferventibus ordibus continuis, sacrisque praecibus praefatos PP.RR. universosque nominatos [ilegible]

$\mathrm{X}$ Fray Seraphis [ilegible]

X Fray Francisco de Pereda, Prets. \& socius.

[Fol.6r. H.2] Yo, Fray Bernardo de Castro, Prior indigno de esta casa de San María de Jesús de la orden de Cartuja extramuros de la ciudad de Granada (usando de la facultad que el Reverendísimo General de la Sagrada Orden de los Predicadores me concedió por la patente atrás escrita, según que por el tenor de ella parece, a que me refiero), señalo y nombro hoy día de San Tiburcio mártir y de agosto 11, del año 1578, el altar de Nuestra Señora de la Antigua, que está en el Capítulo, y al presente sirve de iglesia, para que ante este dicho altar de Nuestra Señora de la Antigua se ganen las indulgencias del Rosario.

Item, desde este mismo día escribo en este libro consecutivamente los nombres de los monjes conventuales, y de los frailes legos, donados y prebendarios que pidieren ser escritos conforme a la orden dada por los instituidores de la Santa Cofradía del Rosario de Nuestra Señora, para que queden admitidos por cofrades, y rezando cada semana el rosario hayan de gozar y gocen de todos los perdones e indulgencias concedidas a los cofrades del Rosario, y sean participantes de todas las misas, oraciones, ayunos, disciplinas, trabajos y buenas obras que mediante la Gracia divina por toda la Cristiandad hicieren, así los cofrades del Rosario, como los frailes y monjas de la Sagrada Orden de los Predicadores. 
Y en nombre de Dios me escribo primeramente a mí el dicho fray Bernardo de Castro, y a mi hermano don Pedro de León, monje que fue Cartujo ya difunto, y a mis hermanos Juan de Castro, y Martín López de Castro, y Manuel de León, difuntos a los cuales escribo con intención que tengo de rezar por ellos el Rosario para que ganen per modum sufragii las gracias e indulgencias y bienes espirituales de la Cofradía del Rosario. Y con esta misma intención escribo a mi abuela Catalina Ruiz, y a mi padre Martín López de Castro, y a mi madre María Ortiz, y a mi hermana Juana Ortiz, difuntos que Dios haya.

Item, escribo al Padre don Pedro Manrique, monje antiguo de esta casa.

Y al Padre don Melchor Téllez.

Y al Padre don Gonzalo de Perea, el cual nombró para que aquí se escribiesen a su padre Pedro González, y a su madre Aldonza Añez, y otras dos ánimas de difuntos cuales Dios aceptare y tuviere por especiales.

Y al Padre don Francisco Muñoz, el cual pidió le escribiesen aquí a su padre Pedro Fernández Hidalgo, y a su madre Francisca Rodríguez, y a un hermano suyo, Pedro Hidalgo, y Francisca Rodríguez su hermana.

Item al Padre don Diego Rodríguez.

Item fray Francisco Preciado.

Item al Padre don Juan de Lora, el cual pidió se escribiesen aquí Juan de Lora su padre, y su madre Isabel Muñoz, difuntos.

Item al Padre don Juan de Aranda.

Item al Padre don Juan de Urrutia.

Item al Padre don Tomás Vela.

Item al Padre don Francisco Preciado.

Item al Padre don Manuel de Benavides.

Item al Padre don Juan Pérez.

Item el hermano fray Andrés de Vega, monje indigno.

[Fol.6v. H.2] Item al hermano fray Andrés.

Item al hermano fray García.

Item al hermano fray Juan.

Item al hermano fray Martín.

Item al hermano fray Jerónimo, y a Fernando de Salinas su padre difunto.

Item al hermano fray Agustín.

Item al hermano fray Juan Martínez. (Diego de Huarte y Agustina Huarte. Juan difunto)

Item al hermano Juan de Valle, prebendario.

Item al hermano Alonso Delgado, prebendario. 
[Fol.7r. H.3] Christi nomine invocato

Yo, fray Jerónimo Blanco, Prior indigno de esta casa de Santa María de Jesús de la Orden de Cartuja, extramuros de la Ciudad de Granada (usando de la facultad que el Reverendísimo General de la Sagrada Orden de los Predicadores me concedió por la patente atrás escrita, según que por el tenor de ella parece, a que me refiero), señalo y nombro hoy día de la Anunciación de Nuestra Señora, 25 de marzo de 1610 años, el altar mayor de Nuestra Señora de la Asunción, que al presente está en el Capítulo de los monjes y sirve de Iglesia, para que ante él se ganen las indulgencias del Rosario los que fueren admitidos por cofrades y escritos en este libro.

Y rezando cada semana el Rosario gocen de todos los perdones, y indulgencias concedidas a los cofrades del Rosario, y sean participantes de todas las misas, oraciones, ayunos, disciplinas, trabajos y buenas obras que, mediante la Gracia divina, por toda la Cristiandad hicieren así los cofrades del Rosario como los frailes y monjas de la Sagrada Orden de los Predicadores.

Y desde este mismo día escribo en este libro los nombres mío y de los demás monjes, frailes y donados de esta casa, y los demás que pidieren ser escritos conforme a la orden dada por los instituidores de la dicha Cofradía de Nuestra Señora del Rosario.

Nombres de los monjes

- Fray Jerónimo Blanco, Prior.

- El Padre Don Juan Blanco, Vicario.

- El Padre Don Diego Juárez, huésped.

- El Padre Don Juan de Aranda.

- El Padre Don Antonio Sánchez.

- El Padre Don Andrés de Tovar.

- El Padre Don Francisco de Ulloa.

- El Padre Don Francisco de la Torre.

- El Padre Don Juan Núñez.

- El Padre Don Andrés de Vega.

- El Padre Don Sancho de Noriega.

- El Padre Don Diego de Solís.

- El Padre Don Melchor de Orbara.

- El Padre Don Francisco de Ardanza.

- El Padre Don Juan de Rojas.

- El Hermano Don Bruno Bautista.
- El Padre Don Diego de Medrano.

- El Padre Don Juan de Asián.

- El Padre Don Juan Navarro.

- El Padre Don Miguel de Palacios.

- El Padre Don Alonso Papalvo, huésped.

- El Padre Don Ignacio Guindal.

- El Padre Don Mateo de Varo.

- El Padre Don Juan Molano.

- El Padre Don Pedro Manuel.

- El Padre Don Juan de Aguilera.

- El Padre Don Baltasar de Oyuela.

- El Padre Don Bartolomé Garpo.

- Fray Diego de Palacio. [Tachado]

- El Padre Don Juan de la Cuesta.

- El Padre Don Juan de Tapia.

- El Padre Don Luis de Cuadros.

- El Padre Don Pedro Laínez.

- El Padre Don Diego de Mesa. 
- El Padre Don Juan de la Torre. _ - Fray Joseph de Montoro.

- El Padre Don Esteban de Escala. - El Padre Don Antonio de Llano.

- El Padre Don Vicente Milán. _ - El Padre Don Francisco del Corral.

[Fol.7v. H.3] Nombres de los frailes

- Fray Agustín Bruno.

- Fray Juan Martínez Rascafría.

- Fray Juan Martínez Calvito.

- Fray Sebastián de Huerta.

- Fray Juan Marín.

- Fray Antonio de Valverde.

- Fray Gabriel González.

- Fray Matías.

- Fray Antonio Varea.

- Fray Sebastián de Mestanza.

- Fray Pedro del Castillo.

- Fray Sebastián de Olivares, novicio.

- Fray Pedro de Torres.

- Fray Pedro de la Cruz.
- Fray Alonso de San Juan.

- Fray Bruno Urbano.

- Fray Fernando Ruiz.

- Fray Juan de Celaya.

- Fray Diego de Gadea.

- Fray Gregorio Bautista.

- Fray Bartolomé de Arjonilla.

- Fray Francisco Ruiz.

- Fray Pedro de la Madre de Dios.

- Fray Juan Pascual.

- Fray Pedro el Recio.

- Fray Sebastián Elices.

- Fray Alonso de Medina, huésped.

- Fray Miguel de Natal Jiménez.

\section{[Fol.8r. H.4] Donados}

- El Hermano Cristóbal.

- El Hermano Juan Bautista,

- El Hermano Pedro Muñoz. huésped.

- El Hermano Francisco Muñoz.

- El Hermano Juan de Lara.

- El Hermano Juan Carrasco.

- El Hermano Peralta.

- El Hermano Fernando Aguado.

- El Hermano Alonso de Cobaleda.

- El Hermano Miguel de Tamayo.

- El Hermano Pedro Criado.

- El Hermano Francisco de Olivares.

- El Hermano Juan Coronado.

- El Hermano Juan Jerónimo Lasterra.

- El Hermano Francisco de Céspedes.

Yo, Fray Francisco Ruiz de la Peñuela, Prior de esta Santa Casa y Cartuja de Nuestra Señora de la Asunción y Visitador de la Provincia de Castilla, usando de la facultad que el Reverendísimo General de la Sagrada Orden de Predicadores me concedió por la patente atrás escrita según que por el tenor de ella parece, a que me refiero, señalo y nombro hoy, día del Patriarca San Benito de marzo 21 del año de 1694, el altar de Nuestra Señora de la Compasión, que está en el cuerpo de la Iglesia, al subir la grada junto al evangelistero, para que ante el dicho altar de la Compasión se ganen las indulgencias del Santísimo Rosario. 
Item, desde este día escribo en este libro consecutivamente los nombres mío y de los Padres monjes, conversos y donados que pidieren ser escritos conforme a la orden dada por los instituidores de la Cofradía del Rosario, para que queden admitidos por Cofrades y rezando cada semana el Rosario hayan de gozar y gocen de todos los perdones e indulgencias concedidas a los Cofrades del Rosario, y sean participantes de todas las Misas, oraciones, [Fol.8v. H.4] ayunos, disciplinas, trabajos y buenas obras que mediante la divina gracia por toda la Cristiandad hicieren así los Cofrades del Rosario como los Religiosos y Religiosas de la Sagrada Orden de Predicadores.

X Fray Francisco Ruiz de la Peñuela.

X Fray Basilio Bravo.

- Padre Don Bartolomé de la Puente. - Fray Andrés Alharilla, converso.

- Padre Don Juan Matías.

- Fray Manuel Cantero, converso.

- Padre Don Andrés Vela.

- Padre Don Manuel González.

- Padre Don Manuel Bardales.

- Padre Don Juan Matellano.

- Padre Don Manuel Valero.

- Padre Don Isidro Hermida.

- Fray Joseph López Contreras, converso.

- Fray Bruno Simón, converso.

- Hermano Francisco Corpas.

- Hermano Joseph Sánchez Romero.

- Hermano Manuel de Jerez y Borja.

- Padre Don Joseph de San Bruno.

- Padre Don Plácido García.

- Padre Don Juan Mayor.

- Fray Cecilio Pérez, converso.

- Fray Juan de Matas, converso.

- Hermano Juan del Campo y Espejo.

- Padre Don Pedro de Villa, huésped.

- Fray Manuel Galán, converso.

- Padre Don Francisco de Bustamante.

[Fol.9r. H.5] Yo, Fray Joseph de Cheverri, Prior de esta Santa Casa de Nuestra Señora de la Asunción, extramuros de esta ciudad de Granada, y Visitador de la Provincia de Castilla, usando de la facultad que el Reverendo General del Sagrado Orden de Predicadores me concedió por la patente atrás escrita, según que por el tenor de ella parece, a que me refiero, señalo y nombro hoy, día de Nuestra Señora y de julio 2 de 1695, el Altar de la Compasión de dicha Virgen, que está en el cuerpo de la Iglesia, al subir la grada junto al evangelistero, para que ante dicho altar se ganen las indulgencias del Santísimo Rosario.

Item, desde este mismo día escribo en este libro consecutivamente los nombres mío, y de los Padres Monjes, Conversos y Donados que pidieren ser escritos, conforme a la orden dada por los instituidores de la Cofradía del Santísimo Rosario, para que queden admitidos por Cofrades, y rezando cada semana el Rosario, hayan de gozar y gocen de todos los perdones e indulgencias concedidas a los Cofrades del Rosario y sean participantes de todas las 
Misas, oraciones, ayunos, disciplinas, trabajos y buenas obras que mediante la divina gracia, por toda la Cristiandad, hicieren así los Cofrades del Rosario, como los Religiosos, y Religiosas del Orden de Predicadores.

$\mathrm{X}$ Fray Joseph de Cheverri.

Todos los Cofrades inmediatamente escritos viven y se suponen aquí asentados, y los que vinieren se asientan como sigue:

- El Hermano Francisco Juárez, Donado.

- El Hermano Francisco García, Donado.

- Padre Don Francisco de Bustamante.

- [Fol.9v. H.5] Padre Don Francisco Panduro, huésped.

- El Hermano Antonio Tejera.

- El Hermano Agustín Feo de Caraballo.

- El Padre Don Juan Suárez, profesó de novicio siendo huésped en esta casa de Granada.

- Fray Nicolás Ambrosio de Castro.

Yo fray Nicolás Ambrosio de Castro, prior de esta Santa Cartuja de Nuestra Señora de la Asunción, extramuros de esta Ciudad de Granada, Visitador de esta Provincia de Castilla, usando de la facultad que el Reverendísimo Padre General de la Sagrada Orden de Predicadores me concedió por la patente supra scripta, según que por el tenor de ella parece, a que me refiero, señalo y nombro a día 2 de octubre del año 1697, por el Altar de Nuestra Señora del Rosario, el que antes tenía la advocación de la Compasión de Nuestra Señora, que está en el cuerpo de la Iglesia al subir la grada junto al evangelistero, para que ante dicho altar se ganen las indulgencias del Santísimo Rosario. A 2 de octubre del año de 1697.

X Fray Nicolás Ambrosio de Castro.

- El Padre Don Juan Matías.

- El Padre Don Isidro de la Hermida.

- El Padre Don Ambrosio Mesía, - El Padre Don Joseph de San Bruno. Vicario.

- Fray Basilio Bruno, Vicario.

- El Padre Don Bartolomé de la Puente.

- ElPadre Don Francisco Bustamante.

- El Padre Don Francisco Panduro, huésped.

- [Fol.10r. H.6] El Padre Don Francisco Ruiz de la Peñuela.

- El Padre Don Joseph de Cheverri.

- El Padre Don Plácido García.

- El Padre Don Manuel González.

- El Padre Don Juan Matellano.

- El Padre Don Manuel Valero.

- El Padre Don Juan Suárez, huésped.

- El Padre Don Antonio Blanes, huésped.

- El Padre Don Juan de Espinosa, huésped.

- El Padre Don Joseph Cornejo, huésped. 
- El Padre Don Pedro Englando, - El Padre Don Juan Bautista de la Hoz. huésped.

- El Padre Don Juan Caballero.

- El Carísimo Don Pedro Andrés. _ - El Padre Don Manuel Torcuato.

\section{Conversos}

- Fray Cecilio Pérez.

- Fray Juan de Mata.

- Fray Manuel Galán.

- Fray Andrés de Alharilla.

- Fray Manuel Cantero.
- Fray Joseph López.

- Fray Bruno Simón.

- Fray Francisco de Corpas.

- Fray Joseph Sánchez Romero.

\section{$\underline{\text { Donados }}$}

- El Hermano Manuel de Jerez.

- El Hermano Juan del Campo.

- El Hermano Francisco Juárez.

- El Hermano Antonio Tejera.

- El Hermano Agustín Feo de Caraballo.

- El Hermano Pedro Ramos.

- El Hermano Leandro Paredes.

- El Hermano Diego de Ochoa.

- El Hermano Ignacio Álvarez.

- El Hermano Joseph de Pablo.
- El Hermano Jaime Aguilar.

- El Hermano Joseph Matías Sánchez.

- El Hermano Diego de Cires Calderón.

- [Fol.10v. H.6] El Hermano Asensio Gallardo.

- El Hermano Manuel de Araujo.

- El Hermano Joseph Martínez.

- El Hermano Antonio de la Fuente.

- El Hermano Pedro Marín.

- El Hermano Francisco Landínez.

\section{Conversos}

- Fray Francisco de San Joseph.

[Nueva lista de padres monjes]

- [Fol.11r. H.7] El Padre Don Juan de Aguilar.

- El Padre Don Bernardo de la Plaza.

- El Carísimo Don Francisco Gallego.

- El Padre Don Nuño Núñez de Villavicencio.
- El Padre Don Millán Grijalbo.

- El Carísimo Don Francisco Francos de Miranda.

- El Carísimo Don Francisco Pérez de Montoya.

- El Padre Don Joseph de la Cruz.

Yo Fray Francisco de Bustamante, Prior de esta Santa y Real Cartuja extramuros de esta Ciudad de Granada, y Covisitador de esta Provincia de Castilla, usando de la facultad que el Reverendísimo Padre General de la Sagrada Orden de Predicadores me concedió por la Patente supra scripta según que por el tenor de ella parece a que me refiero, señalo hoy día del Glorioso Pa- 
triarca Santo Domingo, 4 de agosto de este año de 1709, por altar de Nuestra Señora del Rosario el que está en la Capilla pequeña del cuerpo de la Iglesia, al subir la grada junto al evangelistero, para que ante el dicho altar se ganen las indulgencias del Santísimo Rosario, fac ut supra.

X Francisco de Bustamante.

Todos los Cofrades inmediatamente escritos viven y se suponen aquí asentados, y los que vinieren se asientan como se sigue:

- [Fol.11v. H.7] El Padre Don Fran- - El Padre Don Prudencio de Arce. cisco de Bustamante.

- El Padre Don Millán Grijalbo.

- El Padre Don Bernardo de la Plaza. - El Padre Don Manuel Torcuato.

- El Padre Don Juan de Aguilar. - El Padre Don Francisco Gallegos.

- El Padre Don Joseph de Cheverri. - El Padre Don Francisco Francos.

- El Padre Don Ambrosio de Mesa. - El Padre Don Joseph de Santa

- El Padre Don Andrés Vela. Cruz.

- El Padre Don Basilio Bravo. — - El Padre Don Clemente Guerra.

- El Padre Don Nicolás Ambrosio de - El Padre Don Esteban Alvarado. Castro.

- El Padre Don Manuel González. - El Padre Don Cristóbal Gadeo.

- El Padre Don Manuel Valero. - El Padre Don Félix de Badajoz.

- El Padre Don Joseph de San Bruno. - El Carísimo Don Cristóbal Cortés.

- El Padre Don Manuel Franco. _ - El Padre Don Francisco Ugarte.

- El Padre Don Juan Martínez - El Carísimo Don Joseph Arroyo. Caballero. - El Carísimo Don Tomás Esparza.

- El Padre Don Pedro Andrés. _ - El Carísimo Don Alonso Arenillas.

\section{Conversos}

- Fray Cecilio Pérez.

- Fray Andrés de Alharilla.

- Fray Francisco de San Joseph.

- Fray Joseph de Contreras.

- Fray Francisco de Corpas.

- Fray Juan del Campo.

- Fray Antonio Tejera.
- Fray Agustín de Sobremonte.

- Fray Pedro Ramos.

- Fray Joseph Matías Sánchez.

- Fray Joseph Gallardo.

- Fray Manuel de Araujo.

- Fray Joseph Martínez.

- Fray Matías Bravo.

\section{Donados}

- El Hermano Antonio de la Fuente. - El Hermano Juan Rodríguez de

- El Hermano Pedro Marín. Santa María. [Tachado]

- El Hermano Francisco Landínez. - El Hermano Joseph Domínguez.

- El Hermano Pedro Martín. [Tachado] 
[Nueva lista agregada]

- [Fol.12r. H.8] El Padre Don Alonso Fernández.

- El Carísimo Don Sebastián Tormón.

\section{$\underline{\text { Conversos }}$}

[En blanco]

\section{Donados}

- El Hermano Domingo Romay.

- El Hermano Joseph de Baltodano.

- El Hermano Joseph Romay.

- El Hermano Joseph Manuel

- ElHermano Andrés Martín. [Tachado] Vázquez.

[Fol.12v. H.8] Yo Fray Francisco Ugarte Prior de esta Santa y Real Cartuja extramuros de esta Ciudad de Granada, usando de la facultad que el Reverendísimo Padre General de la Sagrada Orden de Predicadores me concedió por la patente supra scripta según que por el tenor de ella parece a que me refiero, señalo hoy día 17 de junio de 1720 por Altar de Nuestra Señora del Rosario el que está en la Capilla pequeña del cuerpo de la Iglesia al subir la grada junto al evangelistero, para que ante el dicho Altar se ganen las indulgencias del Santísimo Rosario, fac ut supra.

X Fray Francisco Ugarte, Prior.

\section{Padres monjes}

- Nuestro Venerable Padre Prior. - - Padre Don Manuel Torcuato.

- Padre Don Juan de Aguilar. — - Padre Don Félix de Badajoz.

- Venerable Padre Don Basilio Bravo. - Padre Don Cristóbal Cortés.

- Padre Don Manuel Valero. _ - Padre Don Joseph de Arroyo.

- Padre Don Joseph de San Bruno. - - [Fol.13r. H.9] Padre Don Tomás

- Padre Don Manuel Franco. de Esparza.

- Padre Don Francisco de Bustamante. - Padre Don Alonso Fernández.

- Padre Don Juan Martínez Caballero. - Carísimo Don Sebastián Tormón.

- Padre Don Pedro Andrés. - Padre Don Alonso Arenillas.

- Padre Don Prudencio de Arce. - - Padre Don Tiburcio Calderón.

- Padre Don Millán Grijalbo. — Carísimo Don Baltasar García Vela.

- Padre Don Esteban de Alvarado. - Padre Don Nuño Núñez de

- Padre Don Cristóbal Gadeo. Villavicencio.

\section{$\underline{\text { Religiosos Conversos }}$}

- Fray Francisco de Corpas.

- Fray Pedro de Ramos.

- Fray Agustín de Sobremonte.

- Fray Matías Bravo. 
- Fray Manuel Araujo.

- Fray Joseph Martínez.

- Fray Antonio de la Fuente.

- Fray Francisco Landínez.

- Fray Pedro Marín.

- Fray Pedro Martín.
- Fray Juan de Santa María.

- Fray Joseph Domínguez.

- Fray Domingo Romay.

- Fray Joseph Romay.

- Fray Juan Giménez Rabanera.

[Fol.13v. H.9] Hermanos Donados

- Hermano Andrés Baltodano.

- Hermano Joseph Baltodano.

- Hermano Joseph Manuel Vázquez.
- Hermano Jerónimo Alonso.

- Hermano Martín Arzallus.

- Hermano Felipe Belmonte.

Yo, Fray Joseph de San Bruno, Prior de esta Santa y Real Cartuja extramuros de esta Ciudad de Granada, usando de la facultad que el Reverendísimo Padre General de la Sagrada Orden de Predicadores me concedió por la Patente supra scripta, señalo según que por el tenor de ella parece, a que me refiero, siendo hoy 5 de junio de 1723 años, por Altar de Nuestra Señora del Rosario, el que está en la Capilla pequeña del cuerpo de la Iglesia al subir la grada junto al evangelistero, para que ante el dicho Altar se ganen las indulgencias del Santísimo Rosario, como se siguen los individuos de esta Santa Casa.

$\mathrm{X}$ Joseph de San Bruno, Prior.

\section{Padres monjes}

- Nuestro Venerable Padre Don Joseph de San Bruno, Prior.

- Venerable Padre Don Basilio Bravo.

- Padre Don Manuel Valero.

- Venerable Padre Don Francisco Ugarte.

- Padre Don Manuel Franco.

- Venerable Padre Don Francisco de Bustamante.

- Venerable Padre Don Juan Martínez Caballero.

- Padre Don Pedro Andrés.

- Padre Don Prudencio de Arce.

- Padre Don Nuño Núñez de Villavicencio.

- [Fol.14r. H.10] Padre Don Millán Grijalbo.
- Padre Don Tiburcio Calderón.

- Padre Don Esteban Alvarado.

- Padre Don Cristóbal Gadea.

- Padre Don Manuel de San Torcuato.

- Padre Don Félix de Badajoz.

- Padre Don Cristóbal Cortés.

- Padre Don Joseph de Arroyo.

- Padre Don Alonso Fernández.

- Padre Don Sebastián Tormón.

- Padre Don Alonso Arenillas.

- Padre Don Baltasar García Vela.

- Padre Don Juan Guzmán.

- Padre Don Antonio García.

- Padre Don Félix Zuera.

- Padre Don Miguel Quintanilla, huésped.

- Carísimo Don Carlos Recarte. 


\section{$\underline{\text { Religiosos Conversos }}$}

- Fray Juan Jiménez de Rabaneda. - - Fray Francisco Landínez.

- Fray Francisco Corpas.

- Fray Pedro Martín.

- Fray Agustín de Sobremonte.

- Fray Juan de Santa María.

- Fray Pedro Joseph Ramos.

- Fray Joseph Domínguez.

- Fray Joseph Matías Sánchez.

- Fray Domingo Romay.

- Fray Manuel de Araujo.

- Fray Joseph Martínez.

- Fray Joseph Romay.

- Fray Antonio de la Fuente.

- Fray Andrés Baltodano.

- Fray Pedro Marín Palomo.

- Fray Joseph Baltodano.

- Fray Pablo del Olmo, huésped.

\section{Hermanos Donados}

- Fray Joseph Manuel Vázquez.

- Fray Jerónimo Alonso.

- Fray Martín Arzallus.

[Nueva lista agregada]
- Hermano Felipe Belmonte.

- Hermano Manuel Valverde.

- Hermano Sebastián de Torices.

\section{[Fol.14v. H.10] Padres Monjes}

- El Carísimo Don Carlos Recarte.

- El Padre Don Tiburcio Ugarte.

- El Padre Don Miguel Mazquiarán.

Yo Fray Juan Bautista de la Hoz, Prior de esta Santa y Real Cartuja, extramuros de esta Ciudad de Granada: usando de la facultad, que el Reverendísimo Padre General de la Sagrada Orden de Predicadores me concedió por la patente supra scripta, según que por el tenor de ella parece, a que me remito, señalo siendo hoy 4 de agosto, día del Glorioso Patriarca Santo Domingo, de 1729, por altar de Nuestra Señora del Rosario el que está en la Capilla pequeña del cuerpo de la Iglesia, al subir la grada junto al evangelistero, para que ante dicho altar ganen las indulgencias del Santísimo Rosario los individuos de esta Santa Casa como se siguen.

X Fray Juan Bautista de la Hoz, Prior.

\section{Padres monjes}

- Nuestro Venerable Padre Prior.

- Venerable Padre Don Joseph de San Bruno.

- Padre Don Prudencio de Arce.
- Padre Don Manuel Torcuato.

- Padre Don Cristóbal Cortés.

- Padre Don Alonso Fernández.

- Padre Don Sebastián Tormón. 
- Padre Don Félix Zuera.

- Padre Don Antonio García.

- Padre Don Miguel Mazquiarán.

- Venerable Padre Don Leonardo Morentino.

- Padre Don Pedro Andrés, Vicario.

- Padre Don Millán Grijalbo.

- Padre Don Cristóbal Gadeo.
- Padre Don Joseph Arroyo.

- Padre Don Francisco Hernando.

- Padre Don Baltasar García.

- Padre Don Tiburcio Ugarte.

- Padre Don Carlos Recarte.

- El Carísimo Don Diego de la Haba, huésped.

\section{[Fol.15r. H.11] Religiosos Conversos}

- Fray Juan de Rabaneda.

- Fray Juan del Campo.

- Fray Agustín de Sobremonte.

- Fray Manuel de Araujo.

- Fray Francisco Landínez.

- Fray Joseph Domínguez.

- Fray Joseph Romay.

- Fray Joseph Baltodano.

- Fray Jerónimo Alonso.

- Fray Pedro Marín.
- Fray Francisco de Corpas.

- Fray Pablo del Olmo.

- Fray Joseph Matías Sánchez.

- Fray Joseph Martínez.

- Fray Pedro Martín.

- Fray Domingo Romay.

- Fray Andrés Baltodano.

- Fray Joseph Vázquez.

- Fray Martín Arzallus.

- Fray Felipe Belmon[te].

\section{$\underline{\text { Hermanos Donados }}$}

- Hermano Manuel Valverde.

- Hermano Sebastián de Torres.

Yo, Fray Antonio Corrochano, Prior de esta Santa y Real Cartuja, extramuros de esta Ciudad de Granada, usando de la facultad que el Reverendísimo Padre General de la Sagrada Orden de Predicadores me concedió por la patente supra scripta, según que por el tenor de ella parece, a que me remito, señalo siendo hoy Primero de julio de 1730 por altar de Nuestra Señora del Rosario el que está en la Capilla pequeña del cuerpo de la Iglesia, al subir la grada junto al evangelistero, para que ante dicho altar [Fol.15v. H.11] ganen las indulgencias del Santísimo Rosario los individuos de esta Santa Casa como se siguen.

X Fray Antonio Corrochano, Prior.

\section{Padres Monjes}

- Nuestro Venerable Padre Prior.

- Venerable Padre Don Joseph de San Bruno.
- Padre Don Juan Matellano.

- Padre Don Pedro Andrés.

- Padre Don Prudencio de Arce. 
- Padre Don Millán Grijalbo.

- Padre Don Manuel Torcuato.

- Padre Don Cristóbal Gadeo.

- Padre Don Cristóbal Cortés.

- Padre Don Alonso Fernández.

- Padre Don Francisco Bullón.

- Padre Don Francisco Hernando.

- Padre Don Sebastián Tormón.
- El Carísimo Don Diego de la Haba.

- Padre Don Baltasar García.

- Padre Don Tiburcio Ugarte.

- Padre Don Félix Zuera.

- Padre Don Antonio García.

- Padre Don Carlos Recarte.

- Padre Don Miguel Mazquiarán.

- Padre Don Juan de Otero.

\section{$\underline{\text { Religiosos Conversos }}$}

- Fray Francisco de Corpas.

- Fray Juan del Campo.

- Fray Pablo del Olmo.

- Fray Agustín de Sobremonte.

- Fray Joseph Matías.

- Fray Joseph Martínez.

- Fray Francisco Landínez.

- Fray Martín de Arzallus.

- Fray Manuel Valverde.

- Fray Felipe de Belmonte.
- Fray Manuel Araujo.

- Fray Joseph Domínguez.

- Fray Domingo Romay.

- Fray Andrés Baltodano.

- Fray Joseph Baltodano.

- Fray Joseph Vázquez.

- Fray Jerónimo Alonso.

- Fray Pedro Marín.

- Fray Cristóbal Jiménez.

- Fray Sebastián García.

[Donados]

- [Fol.16r. H.12] Hermano Sebas- - Hermano Antonio Cepero. [Repetido] tián de Torices.

- Hermano Francisco Terrero.

- Hermano Antonio Cepero.

- Hermano Francisco Terrero. [Repetido]

- Hermano Jerónimo de Torres.

\section{Monjes}

- Padre Don Feliciano Piqueras.

- Padre Don Manuel Armenteros.

- Padre Don Alonso Arenillas.

Yo, Fray Nuño Núñez de Villavicencio, Prior de esta Santa y Real Cartuja extramuros de esta Ciudad de Granada, usando de la facultad que el Reverendísimo Padre General de la Sagrada Orden de Predicadores me concedió por la patente supra scripta, según que por el tenor de ella parece, a que me remito, señalo siendo hoy 30 de julio de 1736 años, por Altar de Nuestra Señora del Rosario el que está en la Capilla pequeña del cuerpo de la Iglesia, al subir la grada junto al evangelistero, para que ante dicho Altar se ganen las indulgencias del Santísimo Rosario los individuos de esta Santa Casa como se siguen. 
X Fray Nuño de Villavicencio, Prior.

[Fol.16v. H.12] Padres Monjes

- Nuestro Muy Venerable Padre Prior. - Padre Don Matías Méndez.

- Venerable Padre Don Joseph de - Padre Don Sebastián Tormón, San Bruno.

- Padre Don Pedro Andrés. Vicario.

- Padre Don Prudencio Arce.

- Padre Don Baltasar García.

- Padre Don Félix Zuera.

- Padre Don Millán Grijalbo.

- Padre Don Antonio García.

- Padre Don Manuel Torcuato.

- Padre Don Miguel Mazquiarán.

- Padre Don Esteban Alvarado.

- Padre Don Manuel Armenteros.

- Padre Don Cristóbal Gadeo.

- Padre Don Antonio Guardia.

- Padre Don Alonso Fernández.

- El Carísimo Don Miguel Mena.

- Padre Don Joseph Arroyo.

- El Carísimo Don Diego Meras.

- Padre Don Francisco Bullón.

- Padre Don Antonio Arenillas.

- Padre Don Feliciano Piqueras. - Padre Don Tiburcio Ugarte.

- Padre Don Domingo Herranz.

- Padre Don Pascual Guitián.

- Padre Don Félix [de] Badajoz.

- Padre Don Bruno de Alloza.

\section{$\underline{\text { Religiosos Conversos }}$}

- Fray Francisco Corpas.

- Fray Juan del Campo.

- Fray Agustín de Sobremonte.

- Fray Joseph Matías.

- Fray Pedro Aceña.

- Fray Manuel Araujo.

- Fray Joseph Martínez.

- Fray Pedro Marín.

- Fray Francisco Landínez.

- Fray Juan de Santa María.

- Fray Joseph Domínguez.
- Fray Domingo Romay.

- Fray Andrés Baltodano.

- Fray Cristóbal Jiménez.

- Fray Joseph Vázquez.

- Fray Jerónimo Alonso.

- Fray Martín de Arzallus.

- Fray Felipe Belmonte.

- Fray Sebastián García.

- Fray Manuel Valverde.

- Fray Alonso Vallejo.

\section{Hermanos Donados}

- El Hermano Sebastián.

- El Hermano Antonio Cepero.

- El Hermano Francisco Terrero.

- El Hermano Juan de Ortega.
- El Hermano Andrés Riesco.

- El Hermano Jerónimo de Ávalos.

- El Hermano Vicente Bastante. 
[Fol.17r. H.13] J.M.J.

Yo, Fray Juan Antonio Martín, Prior de esta Santa y Real Cartuja extramuros de esta Ciudad de Granada, usando de la facultad, que el Reverendísimo Padre General de la Sagrada Orden de Predicadores me concedió por la patente supra scripta, según que por el tenor de ella parece, a que me remito, señalo hoy 22 de julio, día de Santa María Magdalena de 1738, por altar de Nuestra Señora del Rosario el que está en la Capilla pequeña del cuerpo de la Iglesia, al subir la grada junto al evangelistero, para que ante dicho altar se ganen las indulgencias del Santísimo Rosario los individuos de esta Santa Casa como se siguen.

X Fray Juan Antonio Martín Zamora.

\section{Padres Monjes}

- Nuestro Muy Venerable Padre Prior, - Padre Don Luis Carchenilla. Don Juan Antonio Martín Zamora. - Padre Don Alonso Arenillas.

- Padre Don Joseph Arroyo, Vicario. - Padre Don Baltasar García.

- Venerable Padre Don Joseph de - Padre Don Tiburcio Ugarte. San Bruno.

- Padre Don Pedro Andrés.

- Padre Don Prudencio de Arce.

- Padre Don Manuel Torcuato.

- Padre Don Esteban de Alvarado.

- Padre Don Cristóbal Gadeo.

- Padre Don Félix de Badajoz.

- Padre Don Pascual Guitián.

- Padre Don Francisco Bullón.

- Padre Don Alonso Fernández.

- Padre Don Antonio García.

- Padre Don Florencio Mahony.

- Padre Don Manuel Armenteros.

- Padre Don Bruno de Alloza, huésped.

- Padre Don Matías de Méndez.

- Padre Don Miguel Mena.

- Padre Don Antonio de la Guardia.

- Padre Don Diego Meras.

- Padre Don Domingo Herranz.

- Padre Don Esteban Tormón.

- Padre Don Miguel Irigoyen.

- Padre Don Francisco Hernando. - Padre Don Gaspar Pérez.

Prosiguen los Padres Monjes al folio siguiente.

[Fol.17v. H.13] Religiosos Conversos

- Fray Juan del Campo.

- Fray Agustín de Sobremonte.

- Fray Joseph Matías.

- Fray Pedro de Aceña.

- Fray Manuel Araujo.

- Fray Joseph Martínez.

- Fray Pedro Marín.
- Fray Francisco Landínez.

- Fray Juan de Santa María.

- Fray Joseph Domínguez.

- Fray Domingo Romay.

- Fray Andrés Baltodano.

- Fray Cristóbal Jiménez.

- Fray Joseph Vázquez. 
- Fray Jerónimo Alonso.

- Fray Martín de Arzallus.

- Fray Felipe Belmonte.

- Fray Manuel Valverde.
- Fray Alonso Vallejo.

- Fray Antonio Cepero.

- Fray Francisco Terrero.

\section{$\underline{\text { Hermanos Donados }}$}

- El Hermano Sebastián de Torices. - El Hermano Pablo Martínez de

- El Hermano Juan de Ortega. Cuenca.

- El Hermano Andrés Riesco. $\quad$ - El Hermano Joseph Coronel.

- El Hermano Jerónimo de Ávalos. - El Hermano Melchor Yagüe.

- El Hermano Vicente Bastante.

\section{[Fol.18r. H.14] Padres Monjes}

- Padre Don Francisco Pinto.

- Padre Don Fernando Rodríguez.

- Padre Don Luis Núñez.

[Nueva lista]

- Nuestro Muy Venerable Padre - Padre Don Joseph Vázquez. Prior Don Juan Antonio Martín - Padre Don Diego Roldán. Zamora.

- Padre Don Alonso Arenillas.

- Padre Don Joseph Arroyo, Vicario. - Padre Don Luis Carchenilla.

- Padre Don Pedro Andrés.

- Padre Don Baltasar García.

- Padre Don Prudencio de Arce.

- Padre Don Florencio Mahony.

- Padre Don Manuel de San - Padre Don Miguel Mena. Torcuato.

- Padre Don Diego Meras.

- Padre Don Esteban de Alvarado.

- Padre Don Francisco Pinto.

- Padre Don Cristóbal Gadeo.

- Padre Don Gaspar Pérez.

- Padre Don Félix de Badajoz.

- Padre Don Fernando Rodríguez.

- Padre Don Pascual Díaz de Gaitán. - Padre Don Matías Méndez.

- Padre Don Francisco de Santa - Padre Don Joseph Recarte. María.

- Padre Don Juan de Guzmán.

- Padre Don Alonso Fernández.

- Padre Don Miguel Mazquiarán.

- Padre Don Luis Núñez.

- Padre Don Feliciano Piqueras.

- Padre Don Francisco Hernando.

- Padre Don Antonio Guardia.

- Padre Don Sebastián Tormón.

- Padre Don Antonio García.

- Padre Don Francisco Sánchez de Arjona.

- Padre Don Valentín Ibáñez.

- Padre Don Juan Sánchez. 
[Nueva lista sin relación con la anterior; es posterior a 1796]

- [Fol.18v. H.14] El Padre Don Juan González Bermejo.

- El Carísimo Don Antonio Menéndez.

- El Carísimo Don Joseph Manso.

- Padre Don Antonio García.

- Padre Don Antonio Vélez.

- Carísimo Don Joseph Pérez Tobías.

- Padre Don Sebastián Dávila.

- Fray Francisco Morales.

- Padre Don Antonio García.

- Padre Don Bartolomé Herrero.

- Padre Don Manuel Bonifacio Franco.

- Padre Don Pedro Ibáñez.

- Padre Don Tomás Xavier de Esparza, Vicario.

- Padre Don Francisco Guzmán.

- Padre Don Pedro Loranca.

- Padre Don Matías Corroza.

- Padre Don Francisco Guzmán. [Repetido]

- Padre Don Pedro Loranca. [Repetido]

- Padre Don Matías Corroza. [Repetido]

- Padre Don Joseph Pérez Tobías. [Repetido]

- Padre Don Martín Niev[es].

- Padre Don Miguel Blanco.

- Padre Don Santiago Salvador.

- Padre Don Manuel Domingo.

- Padre Don Joseph Mendizábal.

- Padre Don Francisco Trevijano.

- Padre Don Gregorio Lacunza.
- Padre Don Silvestre Rico, profeso de Sevilla.

- Padre Don Joaquín Ternero.

- Padre Don Juan Diego Muñoz.

- Padre Don Norberto Paniagua.

- Padre Don Juan Francisco Gómez Plaza.

- Padre Don Andrés Guerrero.

- Padre Don Miguel Montoya.

- Padre Don Fernando Arias.

- Padre Don Pedro Imirizaldu, Vicario.

- Padre Don Matías Morales.

- Padre Don Antonio García Herreros, profeso de Aniago.

- Padre Don Manuel Higuera.

- Padre Don Antonio Labayru.

- Padre Don Miguel Villanueva.

- Nuestro Muy Venerable Padre Prior Don Salvador de las Muelas.

- Padre Don Miguel Melguizo.

- El Carísimo Don Manuel García Hormaeche.

- Reverendo Don Joseph Obeso, profeso de Sevilla.

- El Venerable Padre Miguel Punzón.

- Nuestro Muy Venerable Padre Don Joseph de Castro.

- El Venerable Padre Don Manuel Arnedillo.

- El Padre Don Félix Manuel Fernández de Reyes.

- Fray José Eustasio de la Torre.

[Fol.19r. H.15] J.M.J.

Yo, Fray Francisco Pinto, Prior de esta Santa Cartuja extramuros de la Ciudad de Granada, usando de la facultad, que el Reverendísimo General de la Sagrada Orden de Predicadores me concedió por la patente supra scripta, según que por el tenor de ella parece, a que me remito, señalo hoy día 14 de julio de 1742, por altar de Nuestra Señora del Rosario el que está en la capilla pequeña del cuerpo de la Iglesia al subir la grada, junto al Presbiterio, al 
lado del Evangelio, para que ante dicho altar puedan ganar las indulgencias del Santísimo Rosario todos los individuos de esta Santa Casa, que de dicho Rosario fueren cofrades.

Y nombro por capellán al Venerable Padre Don Joseph Arroyo, Vicario.

$X$ Fray Francisco Pinto, Prior.

Yo, Fray Francisco Pinto, Prior de esta Real Cartuja extramuros de la Ciudad de Granada, usando de la facultad que el Reverendísimo Padre General de la Sagrada Orden de Predicadores me concedió, según parece de la patente original, que da principio a este libro, a que me remito, señalo hoy día de la fecha, por altar de Nuestra Señora del Rosario, el que está en la capilla pequeña del cuerpo de la Iglesia al subir la grada, junto al Presbiterio, al lado del Evangelio, para que ante dicho altar puedan todos los individuos de esta Santa Casa, Cofrades del Santísimo Rosario, hacer las diligencias para ganar sus indulgencias; señalando como señalo para los demás efectos en la expresada patente contenidos, por Capellán al Venerable Padre Don Juan de Guzmán, Vicario de esta dicha Santa Casa, y para que conste lo firmé en ella a [en blanco] días del mes de septiembre de 1746 años.

X Fray Francisco Pinto, Prior.

[Fol.19v. H.15] Yo, Fray Joseph Arroyo, Prior de esta Real Cartuja, extramuros de la Ciudad de Granada, usando de la facultad que el Reverendísimo Padre General de la Sagrada Orden de Predicadores me concedió, según parece de la patente original que da principio a este libro, a que me remito; señalo hoy día de la fecha por Altar del Rosario el que está en la capilla pequeña del cuerpo de la Iglesia al subir la grada junto al Presbiterio al lado del Evangelio, para que ante dicho Altar puedan todos los individuos de esta Santa Casa, Cofrades del Santísimo Rosario, hacer las diligencias para ganar sus indulgencias, señalando como señalo para los demás efectos en la expresada patente contenidos, por capellán al Venerable Padre Don Antonio Guardia, Vicario de esta dicha Santa Casa; y para que conste, lo firmé en ella a 26 días del mes de julio de 1747 años.

X Fray Joseph Arroyo, Prior.

Yo, Fray Joseph Arroyo, Prior de esta Real Cartuja de Granada, en virtud de la facultad a mí concedida por la patente original que da principio a este libro, señalo y nombro para los efectos contenidos en ella por capellán al Venerable Padre Don Tomás Xavier de Esparza, Vicario de esta dicha Santa Casa; y para que conste, lo firmo en ella a 19 de abril de 1752.

$\mathrm{X}$ Fray Joseph Arroyo, Prior. 
Yo, Fray Tomás Xavier de Esparza, Prior de esta Real Cartuja de Granada, en virtud de la facultad a mí concedida por la patente original que da principio a este libro, señalo y nombro para los efectos contenidos en ella por capellán al Padre Don Joseph Vázquez, Vicario de esta dicha Santa Casa; y para que conste, lo firmo en ella a 5 de agosto de 1752.

$\mathrm{X}$ Fray Tomás Xavier de Esparza, Prior.

[Fol.20r. H.16] Yo, Fray Francisco Pinto, Prior de la Real Cartuja de Granada, en virtud de la facultad a mí concedida por la patente original que da principio a este libro, señalo y nombro para los efectos en ella contenidos por capellán al Padre Don Joseph Recarte, Vicario de esta dicha Santa Casa; y para que conste, lo firmo en ella a 18 de julio de 1754.

X Fray Francisco Pinto, Prior.

Yo, Fray Francisco Pinto, Prior de esta Real Cartuja de Granada, en virtud de la facultad a mí concedida por la patente original que da principio a este libro, señalo y nombro para los efectos en ella contenidos por capellán al Padre Don Joseph Vázquez, Vicario de esta dicha Santa Casa; y para que conste, lo firmé en ella a 16 de octubre de 1755.

X Fray Francisco Pinto, Prior.

Yo, Fray Gaspar Pérez, Prior de esta Real Cartuja de Granada, en virtud de la facultad a mí concedida por la patente original que da principio a este libro, señalo y nombro para los efectos en ella contenidos por capellán al Padre Don Manuel de Armenteros, Vicario de esta Santa Casa; y para que conste, lo firmé en ella a 15 de noviembre de 1758.

X Fray Gaspar Pérez.

Yo, Fray Gaspar Pérez, Prior de esta Real Cartuja de Granada, en virtud de la facultad a mí concedida por la patente original que da principio a este libro, señalo y nombro para los efectos en ella contenidos por capellán al Padre Don Pedro Loranca, Vicario de esta Santa Casa; y para que conste, lo firmé en ella a 3 de diciembre de 1759.

X Fray Gaspar Pérez, Prior.

[Fol.20v. H.16] Yo, Fray Gaspar Pérez, Prior de esta Real Cartuja de Granada, en virtud de la facultad a mí concedida por la patente original que da principio a este libro, señalo y nombro para los fines en ella contenidos por capellán al Padre Don Fernando Rodríguez, Vicario de esta Santa Casa; y para que conste, lo firmé en ella a 9 de junio de 1762 . 
X Fray Gaspar Pérez, Prior.

Yo, Fray Manuel de Aldea, Prior de esta Real Cartuja de Granada, en virtud de la facultad a mí concedida por la patente original que da principio a este libro, señalo y nombro para los fines en ella contenidos por capellán al Padre Don Fernando Rodríguez, Vicario de esta Santa Casa; y para que conste, lo firmé en ella a 28 de febrero de 1771.

X Fray Manuel de Aldea, Prior.

Yo, Fray Manuel de Aldea, Prior de esta Real Cartuja de Granada, en virtud de la facultad a mí concedida por la patente original que da principio a este libro, señalo y nombro para los fines en ella contenidos por capellán al Padre Don Martín Nieto, Vicario de esta Santa Casa; y para que conste, lo firmé en ella a 8 de agosto de 1772 .

X Fray Manuel de Aldea, Prior.

[Fol.21r. H.17] Yo, Fray Domingo de Lastiri, Prior de esta Real Cartuja de Granada, en virtud de la facultad a mí concedida por la patente original que da principio a este libro, señalo y nombro para los fines en ella contenidos por capellán al Padre Don Pedro Imirizaldu, Vicario de esta Santa Casa; y para que conste, lo firmé en ella a 2 de agosto de 1783.

$\mathrm{X}$ Fray Domingo de Lastiri, Prior.

Yo, Fray Lope Núñez de Mendoza, Prior de esta Real Cartuja de Granada, en virtud de la facultad a mí concedida por la patente original que da principio a este libro, señalo y nombro para los fines en ella contenidos por capellán al Padre Don Fernando Arias Gago, Vicario de esta Santa Casa; y para que conste, lo firmé en ella a 9 de diciembre de 1792.

X Fray Lope Núñez de Mendoza, Prior.

Yo, Fray Lope Núñez de Mendoza, Prior de esta Real Cartuja de Granada, en virtud de la facultad a mí concedida por la patente original que da principio a este libro, señalo y nombro para los fines en ella contenidos por capellán al Padre Don Pedro Imirizaldu, Vicario de esta Santa Casa; y para que conste, lo firmé en ella a 9 de noviembre de 1793.

X Fray Lope Núñez de Mendoza, Prior.

[Fol.21v. H.17] Yo, Fray Salvador Muelas, Prior de esta Real Cartuja de Granada, en virtud de la facultad a mí concedida por la patente original que da principio a este libro, señalo y nombro para los fines en ella contenidos por 
capellán al Venerable Padre Don Juan Francisco Gómez Plaza, Vicario de esta Santa Casa; y para que conste, lo firmé en ella a 9 de marzo de 1796.

$\mathrm{X}$ Fray Salvador Muelas, Prior.

[Fol.22r. H.18 - Fol.27v H.23: En blanco]

[Fol.28r. H.24] Religiosos Conversos

- Fray Agustín de Sobremonte.

- Fray Pedro Aceña.

- Fray Joseph Matías.

- Fray Manuel de Araujo.

- Fray Joseph Martínez.

- Fray Pedro Marín.

- Fray Francisco Landínez.

- Fray Juan de Santa María.

- Fray Domingo Romay.

- Fray Andrés Baltodano.

- Fray Cristóbal Giménez.

- Fray Joseph Vázquez.

- Fray Jerónimo Alonso.

- Fray Martín Arzallus.

- Fray Felipe Belmonte.

- Fray Manuel Valverde.

- Fray Alonso Vallejo.

- Fray Antonio Cepero.

- Fray Francisco de la Madre de Dios.
- Fray Juan de Ortega.

- Fray Andrés Riesco.

- Fray Jerónimo de Ávalos.

- Fray Joseph Coronel.

- Fray Pablo Martínez.

- Fray Francisco Morales.

- Fray Antonio Terán.

- Fray Juan de Maza.

- Fray Pedro Ortuño.

- Fray Luis Sanz.

- Fray Francisco Núñez.

- Fray Joseph Romay.

- Fray Basilio de San Miguel.

- Fray Pedro Hermoso.

- El Hermano Manuel Brión. Se fue.

- El Hermano Miguel Arce. Se fue.

- El Hermano Sebastián del Barrio.

- El Hermano Tomás Hermoso. Se fue.

- El Hermano Vicente de la Bella.

[Fol.28v. H.24: en blanco]

[Fol.29r. H.25] Hermanos Donados

- Hermano Sebastián de Torres.

- Hermano Juan de Ortega.

- Hermano Andrés Riesco.

- Hermano Jerónimo de Ávalos.

- Hermano Pablo Martínez de Cuenca.

- Hermano Joseph Coronel.

- Hermano Joseph Aguado. [Tachado]

- Hermano Simón de la Roza, huésped.
- Hermano Alonso Carrión.

- Hermano Joseph Valmaseda.

- Hermano Alonso Gómez.

- Hermano Juan de la Maza.

- Hermano Pedro de Ortuño.

- Hermano Francisco Núñez.

- Hermano Luis Sanz.

- Hermano Joseph Daubis. 
- Hermano Melchor Yaguie.

- Hermano Juan de la Morta.

- Hermano Marcelo de Frías.

- Hermano Manuel Esteban.

- Hermano Joseph López.

- Hermano Lorenzo Ibáñez.

- Hermano Joaquín Sastre del Valle.

- Hermano Félix Esteban Pérez.
- Hermano Pedro Hermoso.

- Hermano Matías Escamilla.

- Hermano Joseph Ortiz Saracho.

- Hermano Juan de la Morta. [Repetido]

- Hermano Manuel Buon.

- Hermano Miguel Díaz de Arce.

- Hermano Sebastián del Barrio.

- Hermano Tomás Hermoso.

[Fol.29v. H.25 - Fol.39v. H.35: en blanco]

[Fol.40r. H.36] Criados del Real Monasterio:

- Manuel Losilla.

- Francisco Quiles.

- Diego Pinel.

- Francisco Contreras.

- Ignacio Escalona.

- Nicolás Escalona.

- Miguel Cirre.

- Juan Díaz.

- Joseph Samarco.

- Gregorio Hita.

- Antonio Luján.

- Agustín Luján.

- Joseph Rodríguez.

- Juan de Vega.

- Felipe del Castillo.

- Miguel Ruiz, capataz.

- Joseph Ayllón García.

- Juan Sánchez.

- Antonio de la Hoz.

- Antonio Santos.

- Sebastián Estella.

- Pedro Martínez.

- Francisco Vílchez.

- Miguel Ruiz, sastre.

- Cecilio Téllez.

- Francisco Viruega.

- Joseph López.

- Juan de Escalona.
- Agustín López.

- Manuel López.

- Antonio Araujo.

- Juan Salinas.

- Joseph Verdejo.

- Joseph Tintín.

- Manuel Pelegrín.

- Manuel Fernández.

- Ignacio Curtidas.

- Juan Gómez.

- Cecilio Huertas.

- Martín Gómez.

- Miguel Losillas.

- Francisco Cánovas.

- Nicolás Gómez.

- Juan de Quesada.

- Félix Romero.

- Salvador de Biedma.

- Luis Arévalo.

- Lorenzo López.

- Joseph López.

- Pedro López.

- Salvador González.

- Joseph Morcillo.

- Salvador de Alcalá.

- Joseph Escalona.

- Francisco Martos.

- Juan Martín. 
- [Fol.40v. H.36] Blas Dávalos.

- Pedro de Tíscar.

- Cristóbal de Ortega.

- Francisco de Huertas.

- Joseph Vargas.

- Manuel de Victoria Fernández.

- Francisco Martín.

- Manuel Amador.

- Antonio Berruguilla.

- Francisco García.

- Antonio de la Fuente.

- Juan de Huertas.

- Juan de Velasco.

- Manuel Martín.

- Francisco Jiménez.

- Andrés Cabezas.

- Joseph Gómez.

- Diego Pinel.

- Francisco Martínez Rescalvo.

- Francisco Joseph García.

- Alonso Eustaquio Morgado.

- Miguel Garrido.

- Juan González.

- Cristóbal de Herrera.

- Simón López.

- Adrián Morcillo.

- Juan de Coria.

- Ramón Martín.

- Juan Cabezas.

- Francisco Santiago.

- Matías Vela.

- Antonio Fernández.

- Alfonso Raimundo Mesías.

- Manuel Martín.

- Nicolás Salinas.

- Juan de Píñar.

- Diego de Píñar.

- Cecilio Baltasar.

- Salvador Ramón.

- Francisco de Cárdenas.
- Diego Pinel.

- Joseph López.

- Pedro Fernández.

- Francisco González.

- Manuel Fernández.

- Ventura Jiménez.

- Alonso García.

- Francisco Martín.

- Manuel López.

- Nicolás de Osma.

- Diego de Huertas.

- Francisco Machado.

- Sebastián Pozuelo.

- Lorenzo García.

- Juan de Aranda.

- Juan Guerrero.

- Antonio Martín.

- Joseph Chicano.

- Juan de Atienza.

- Francisco Hernández.

- Lucas Pérez.

- [Fol.41r. H.37] Gregorio de la Paz.

- Joseph de Torres.

- Antonio Marín.

- Fernando Fernández.

- Lorenzo 'el Valenciano'.

- Ignacio de Rivera.

- Francisco Mellado.

- Juan de Dios.

- Manuel Beltrán.

- Nicolás de Osma. [Repetido]

- Diego de Huertas.

- Francisco Machacado.

- Sebastián Pozuelo.

- Lorenzo García.

- Juan de Aranda.

- Juan Guerrero.

- Antonio Martín.

- Joseph Chicano.

- Juan de Atienza. 
- Francisco Hernández.

- Lucas Pérez.

- Fernando Fernández.

- Lorenzo Ruiz.

- Ignacio de Rivera.

- Francisco Mellado.

- Juan de Dios. [Repetido]

- Manuel Beltrán.

- Antonio Núñez.

- Francisco Junquera.

- Joseph López.

- Manuel Cerón.

- Cristóbal Rodriguez.

- Antonio García.

- Juan García.

- Antonio de la Peña.

- Antonio de Hita.

- Francisco Hernández.

- Cristóbal Fernández.

- Bartolomé de la Fuente.

- Damián Vidal.

- Pedro Curtías.

- Miguel González.

- Juan Martín.

- Pedro Martín.

- Antonio de Torres.

- Juan Vázquez.

- Manuel Méndez.

- Antonio Milán.

- Francisco Martín.

- Manuel Toribio López.

- Felipe de Coria.

- Manuel de Arroyo.

- Fernando Núñez.

- Pedro García.

- Hipólito Martín.

- Miguel González.

- Pedro Ruiz.
- Alonso Nucete.

- Blas Obispo.

- Pedro Arroyo.

- Francisco de Cánovas.

- Fernando Marín.

- Félix Polo.

- Manuel Cánovas.

- Manuel Martín.

- Manuel Ledesma

- Jacinto Bueno.

- Agustín de Quesada.

- Antonio Serrano.

- Francisco Díaz.

- Juan Carlos Perales.

- Joseph Gómez.

- Manuel Calleja.

- Manuel Jiménez.

- Ignacio Velasco.

- Diego Ramón.

- Esteban Berbel.

- Manuel Redondo.

- Antonio Martín.

- Francisco Gómez.

- Francisco Molina.

- Francisco González.

- Manuel Muñoz.

- Francisco Ruiz.

- Martín de Echegaray.

- Dionisio Gómez.

- Agustín Gómez.

- Antonio Gómez.

- Antonio Luis Gómez.

- Rafael Gómez.

- Martín Gómez.

- Manuel Medina.

- Sebastián Díaz.

- Josef Fraile.

- Gabriel Martín.

[Fol.41v. H.37 - Fol.55v. H.51: en blanco] 


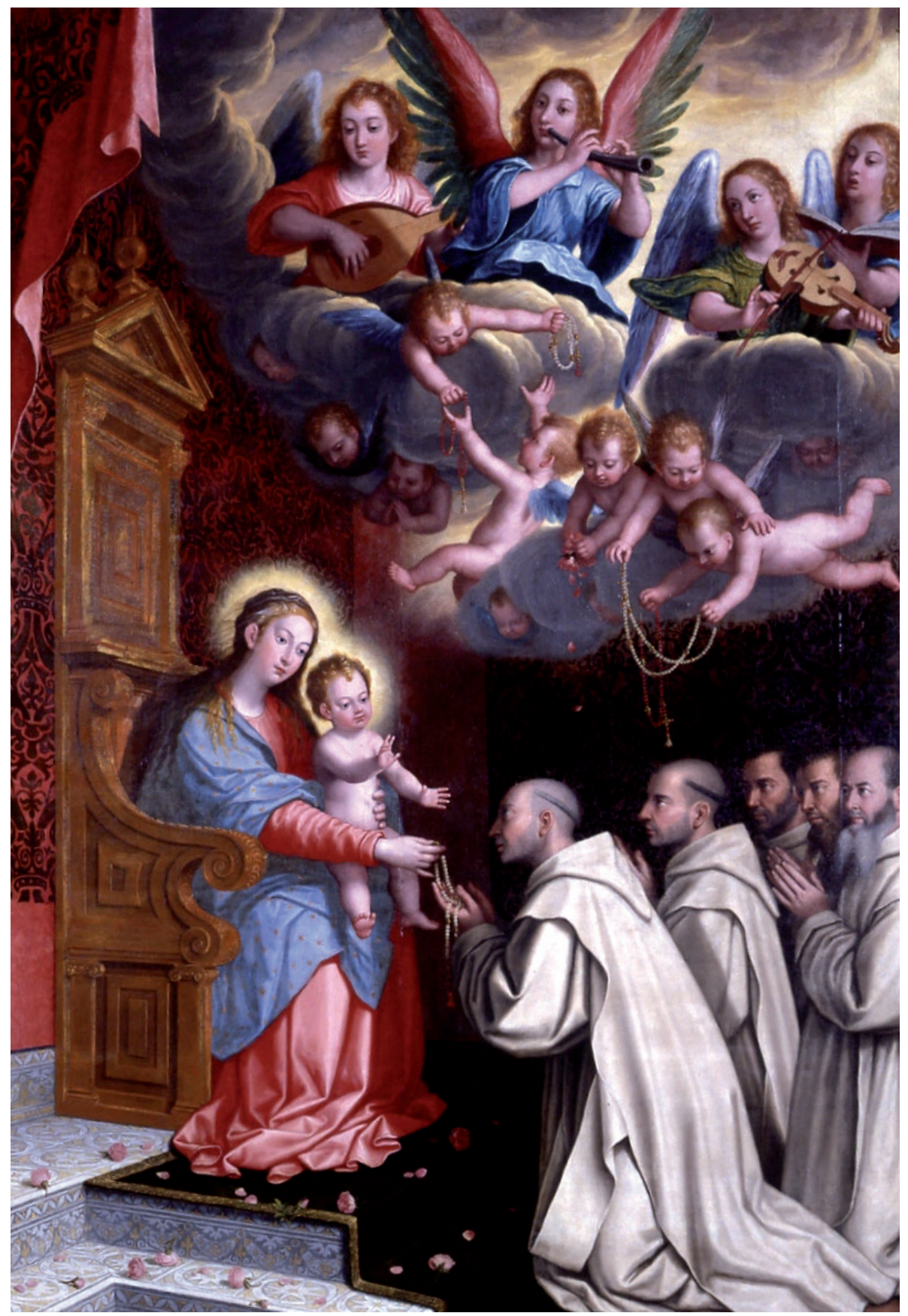

Fig. 1. Sánchez Cotán, J. (1603-1627), Aparición de la Virgen del Rosario a los cartujos. Localización y foto: Museo de Bellas Artes de Granada. 
El Libro de los Cofrades del Santísimo Rosario de la Cartuja...

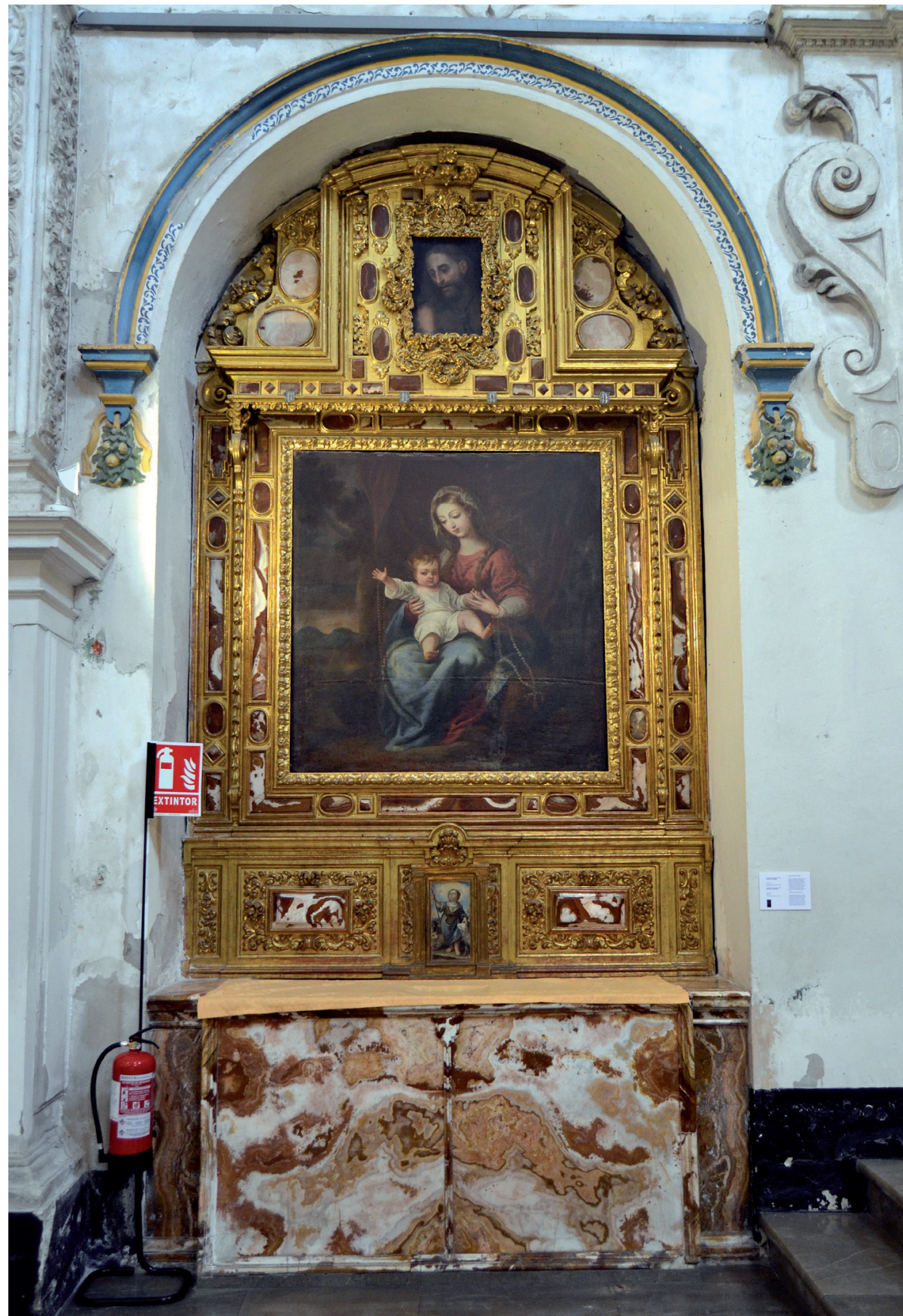

Fig. 2. Altar de la Virgen del Rosario presidido por el lienzo homónimo de Bocanegra (h. 1676; retablo y altar son de 1730). Foto: José Antonio Díaz. 


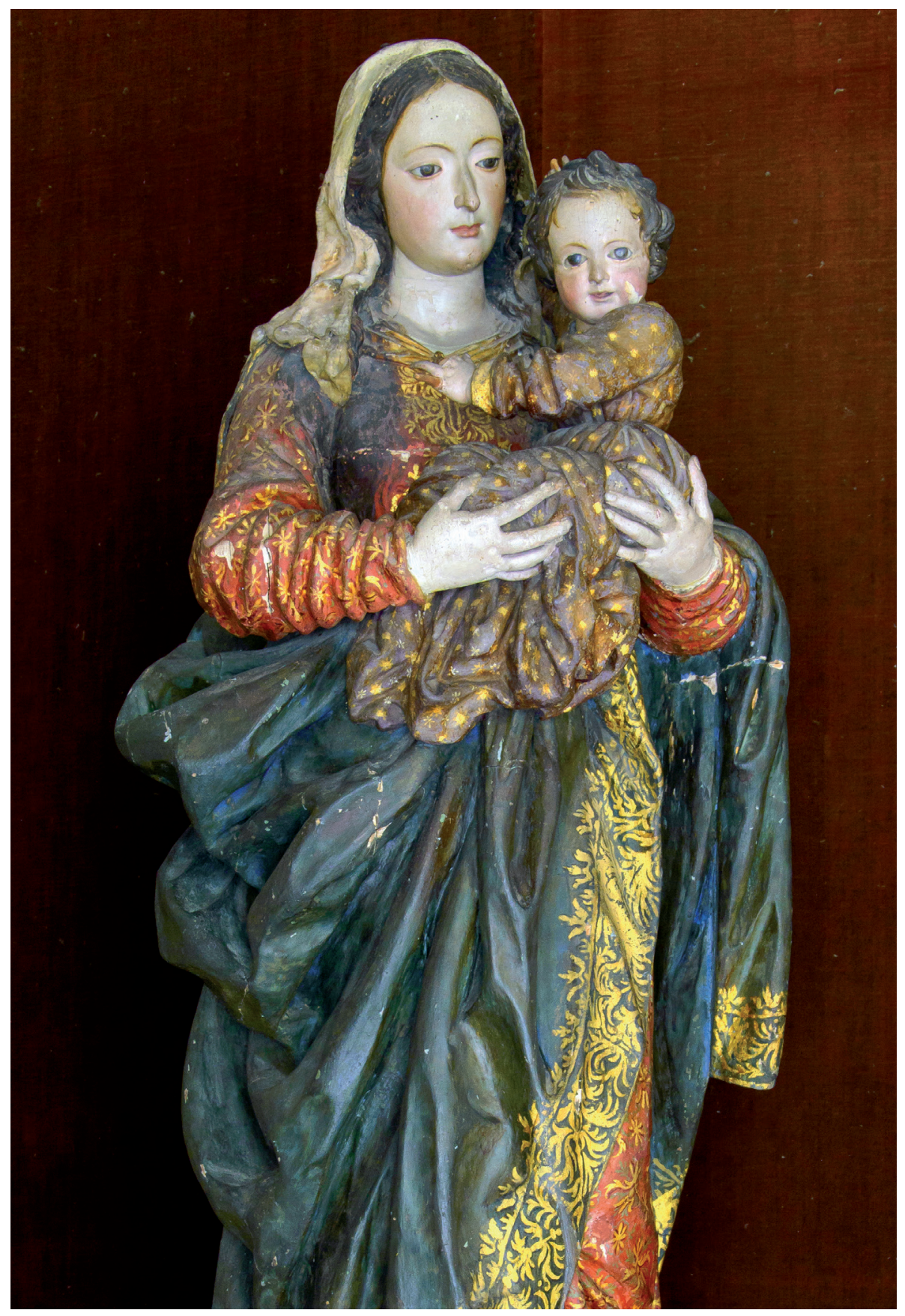

Fig. 3. Risueño Alconchel, J. (1710-1712), Virgen del Rosario [detalle], Cartuja de la Asunción. Foto: José Antonio Díaz. 